\title{
Article \\ Exploring Generational Private Mobility Paradigm Shifts through Duration Modeling Analytics: A Greek Case Study
}

\author{
Ioannis Fyrogenis *(D) and Ioannis Politis \\ Transport Engineering Laboratory, School of Civil Engineering, Aristotle University of Thessaloniki, \\ 54124 Thessaloniki, Greece; pol@civil.auth.gr \\ * Correspondence: fyrogeni@civil.auth.gr
}

check for updates

Citation: Fyrogenis, I.; Politis, I. Exploring Generational Private Mobility Paradigm Shifts through Duration Modeling Analytics: A Greek Case Study. Future Transp. 2021, 1, 54-81. https://doi.org/10.3390/ futuretransp1010005

Academic Editor: Armando Carten

Received: 10 March 2021

Accepted: 22 April 2021

Published: 6 May 2021

Publisher's Note: MDPI stays neutral with regard to jurisdictional claims in published maps and institutional affiliations.

Copyright: (c) 2021 by the authors. Licensee MDPI, Basel, Switzerland. This article is an open access article distributed under the terms and conditions of the Creative Commons Attribution (CC BY) license (https:/ / creativecommons.org/licenses/by/ $4.0 /)$.

\begin{abstract}
In this paper, we explore lifetime private mobility milestones in Greece and identify the factors that affect them, to explore the everchanging mobility landscape. In total, five archetypal private mobility milestones were examined: the age of getting a car driving license and the period until getting a car following that; the age of getting a motorbike driving license; the age of getting a first bicycle as an adult; and the age of first traveling by airplane. To this end, duration modeling and namely Kaplan-Meier and Cox Proportional Hazards models were developed. Results show that mobility paradigms are evolving and are affected by a wide array of factors. Generational differences are particularly highlighted, as younger travelers are less likely to get a car driving license or a car sooner but are more likely to get a bicycle as adults. Higher parents' income diversely affects multiple mobility milestones. Growing up in rural locations and sustainable transport awareness also significantly affect mode choice related mobility milestones. Men were more likely to get both car and motorbike driving licenses at younger ages. The above results highlight the mobility profiles of Greek citizens and the factors that affect them, while offering insights into a future mobility landscape.
\end{abstract}

Keywords: duration analysis; lifetime mobility milestones; mobility norms; mobility paradigm shift; travelers' behavior; modelling behavior

\section{Introduction}

The socioeconomic and technological changes and advances societies face, with increasingly intensive rate, are reflected on every facet of human activity. Due to the everchanging nature of everyday life, economic welfare and the improved availability and reliability of transport services, there are discrete differences in transport preferences and choices between individuals with different socioeconomic characteristics, as well as between different generations of travelers. Understanding the mechanisms behind those life-changing choices is important, as it shapes the mobility behavioral profile of each traveler and the overall profile of their greater community. Utilizing that information, it is possible to predict future trends and gain a better understanding of mobility issues and challenges allowing for a more future-proof, long term and robust transport planning. At the same time, it becomes possible to quantify and measure the impact of previously implemented policies on current behavioral trends, such as environmental awareness.

Many established mobility trends, such as car ownership and usage, have been significantly altered. For example, Kuhnimhofm et al. [1] showed that the historic trend regarding increased motorization and automobile usage for young Germans and Britons does not exist anymore. During the last decade they have decreased automobile travel, obtained fewer driving licenses and registered fewer vehicles. This was not caused just by decreasing car access, but also by increasingly multimodal behavior of car owners as well. The paper indicated that the decrease was more intense for male drivers, but also that there were "remarkable similarities between travel behavior changes in Germany and Great Britain", which suggests that those changes may not be longitudinally limited or 
affected by local idiosyncrasies, but indicative of a fundamental shift in travel behavior, affecting multiple societies. Expanding on their previous work, Kugnimhof et al. [2] noticed this trend was persistent in a wider variety of culturally different countries. More recent studies [3] have shown that commuters with higher incomes have increased odds of not choosing a car for their commuting, contrary to expectations. Studies by Clark et al. have shown that car ownership is related to changes in household compositions, car driving license availability, employment status and income changes [4] and that shifting to car commuting from other modes of transport significantly increased with the distance from work, while shifting away from car commuting was connected with a pro-environmental attitude [5]. Other studies have explored whether environmental sensibilities are the main reason behind declining driving license acquisition rates and concluded that while they were a factor, but not as important as employability, available funding or costs associated with driving [6,7]. Pojani et al. [8] found that the younger generations in Tirana (Albania) still purchase cars to improve their social standing. Similarly, social norms have been found to significantly affect students' intention of purchasing a car [9]. Delbosc and Currie [10] used record data from 14 countries and found a steady decline in the likelihood of obtaining a driving license in nine of them. The recorded average annual decline was $0.6 \%$. Main contributors to this decline, are changes in living arrangements and stages of life, car affordability changes, increased electronic communication and graduated driver licensing systems. The declining trend does not seem to be solely caused by one of those factors, but rather is the result of multiple causes, based on the evidence. Contrary to that, Newbold and Scott [11] showed that, based on current trends as well as those of previous generations, the percentage of Canadian Millennials with active driving licenses is increasing tending to reach those of previous generations. Apart from generational differences, other sociodemographic characteristics have proved to substantially affect attitude towards using cars. Oakil [12] found that while impactful life events significantly influence car access for women, the same isn't observed for men.

The ongoing fluctuations in transport habits, are not limited to automobile use. According to the European Cyclists' Federation [13], there are increasing trends in bicycle sales in many European countries, as well as a simultaneous decrease in passenger car registrations. Adolescents' intentions to commute by car or bicycles as adults has been linked with characteristics such as their gender, place of residence, current mode choice and their parents' travel behavior [14]. In Greece, the acceptance of a bike-sharing system in a small town was found to be affected by the age and gender of the respondents, their primary mode of transport and how effective it would be towards reducing congestion [15]. Furthermore, during the last decades, air travel demand is steadily increasing, especially after the worldwide airline privatization which led to more affordable fares [16].

The dynamic nature of travel habits and choice behavior with respect to societal differentiations between successive generations of travelers, described above, may act as a barrier to efficiently model and interpret human mobility norms. This feat often is difficult, because of society's development, new emerging, disruptive technologies, and other unpredictable factors. Being able to understand the process by which older and established mobility norms are evolving for younger generations of users with diversified needs and habits would not only help outline the future mobility landscape, but also pinpoint the specific characteristics that are responsible for those changes.

The onset and development of different mobility norms, especially regarding the use of private means of transport, can be identified by analyzing the occurrence of important private mobility milestones in someone's life. For the purposes of this paper, mobility milestones are defined as events that occurred during someone's life that could significantly impact his behavior and his future mobility profile. For example, obtaining a driving license is considered an important milestone for someone's mobility habits and will most probably radically change his future transport behavior. Consequently, a society where people are developing the habit of getting their driving licenses at an older age, can develop into a 
society that does not primarily depend on private transport means but can instead is more receptive towards public transport or shared mobility alternatives [17].

While specific aspects of private mobility norms have been examined by the pertinent literature, there have not been enough attempts towards holistically examining how those trends evolve throughout the years and whether there are differences between discrete social groups and generations. This paper attempts to examine the onset of private mobility milestones showcasing a Greek case study and explore the factors that affect them, through the use of a more concise and spherical methodology. Greece is a mountainous peninsula that is part of Eastern Europe and the Balkans. About $80 \%$ of the country's population resides in urban areas [18]. The country went through a severe economic crisis, following the worldwide financial crisis of 2007-2008. The recession that followed it had a wide array of economic, humanitarian, and social repercussions, including but not limited to an increased suicidal rate [19-21]. Car ownership per 1000 inhabitants explosively grew and almost doubled from 1990 to 2009, but was halted by the economic crisis and remained stable until the year of the study (2017) [22]. Sustainable mobility trends, such as carsharing or cycling and bike-sharing that have been widely adopted in other countries seem to be lagging behind in Greece [23-25]. Older and recent studies have shown that the cycling modal share is very low (lower than $1.5 \%$ ), while car usage is high even for short trips. About $65 \%$ of all car trips only had one passenger on board [24,26].

The concurrent effect of the economic crisis, the increased reliance on private mobility, along with the rapid evolution societies are undergoing in a global level, render Greece's case study particularly interesting. Several factors, both local and global, personal and societal could act in tandem and affect long-term choices Greek citizens made regarding their private mobility needs. While it would be difficult to map such widespread effects, examining how different groups of the Greek population shape their mobility profile during periods of volatile change could shed light on the mechanisms that shape those choices. Attempting to cover a wide variety of indicators of private transport behavior the mobility milestones that were examined are:

- The age of getting a car driving license.

- The period since a user obtains a driving license until he/she gets his/her first car.

- The age of getting a motorbike driving license.

- The age of getting a bicycle as an adult.

- The age of travelling by airplane for the first time.

Getting a driving license for a motorized vehicle, can be a significant investment in time and resources and makes modes of transport that were previously inaccessible available, and can signify the intention to considerably use that mode of transport in the future. Furthermore, getting a car is also a major expenditure, that can signify the intend to depend on that vehicle in the immediate future. Getting a bicycle is only examined for adults, since for the majority of the years before adulthood getting a bicycle would have been a "captive" choice, since all other private modes of transport-and most importantly the private car-are not available as a choice. Finally, travelling by airplane is also included, since-as previously mentioned-there have been significant advances in air travel in recent years that are worth exploring.

Towards that, this paper utilizes duration analysis to decode the patterns of lifetime mobility norms and highlight the respective mobility milestones correlating their appearance with various user socio-economic characteristics. Given that many of the examined trends seem to have been affected by lifestyle changes, it is expected to identify and further explore strong correlations, between transport choices and groups of users with certain socio-economic characteristics.

It should be noted that all the above-mentioned milestones could be considered as events that may or may not occur during individual's lifetime. To develop reliable duration models, there is need to include cases for which the event(s) has already occurred but also cases where the event(s) hasn't occurred yet. For example, when examining the age of getting a driving license, it would be biased to select only a pool of cases that have already 
obtained a driving license, because it would exclude the cases that for some reason haven't obtained yet their driving license but may obtain one in the future.

The structure of the rest of the paper's chapters is laid out as follows. Section 2 presents the materials and methods that were used for the analysis. Section 2.1 gives a summary of duration analysis literature and why it was the analysis tool of choice and Section 2.2 presents the data that were utilized for the paper and the methodology that was followed. Section 3 presents the results of the duration analysis with each section presenting one private mobility milestone and Section 3.6 taking a look into the mutual evolution of different mobility milestones through time. Finally, Section 4 presents the results of the analysis more concisely, explores common themes between different mobility milestones and expands the discussion on them.

\section{Materials and Methods}

\subsection{Duration Analysis}

Duration analysis or survival analysis, as it is most commonly known, is a branch of statistics for which the outcome variable of interest is the time until the occurrence of a well-defined event [27]. Hazard-based duration models have been extensively used in biometrics and industrial engineering fields, for the determination of causality in duration data [28]. There have also been some applications in the transportation field, in accident analysis [29-31], pavement durability [32,33], drivers' behavior [34-37], illegal crossing of signalized intersections $[38,39]$ and travelers' activity $[30,40,41]$.

In duration analysis, it is often needed to take into consideration the problem of censored observations. For censored events, the exact period, until the examined event's occurrence, isn't known. Depending on the analyzed event, there can be left censoring (when the event has already occurred before the observed time t but the exact time isn't known) or right censoring (when the event might occur after the observed time $t$ ). Duration analysis methods and models are specifically suited to handle the problem of censored events, utilizing both censored and uncensored data [42].

Two quantitative terms, critical for performing duration analysis, are the survivor function $\mathrm{S}(\mathrm{t})$, given by Formula (1) and the hazard function $h(t)$, given by Equation (2). $\mathrm{S}(\mathrm{t})$ is the probability that the event has not occurred after some specified time t. The survivor function provides crucial information for the assessment of duration data, since calculating the survival probability for the different values of $t$ offers an efficient summary of the data. The hazard function $h(t)$ "gives the instantaneous potential per unit time for the event to occur", given that it has not occurred up to time t. The two functions provide information on the two different facets of duration analysis (the probability of the event not occurring and the probability of the event occurring) and can be considered opposites [43]:

$$
\begin{gathered}
S(\mathrm{t})=\mathrm{P}(\mathrm{T}>\mathrm{t}) \\
h(t)=\lim _{\Delta t \rightarrow 0} \frac{P(t \leq T \leq t+\Delta t \mid T \geq t)}{\Delta t}
\end{gathered}
$$

The Kaplan-Meier method of duration analysis, given by Equation (3), is a nonparametric, very commonly used, method for the appraisal of duration data. Kaplan-Meier survival curves provide concise and easy to interpret information about the duration data. The limitation of the method is that it cannot be used for predictions beyond the durations observed in the available data. This model compares the survival curves of different categorical explanatory variables, by stratifying the data. Using the log rank test, the statistical importance of the difference between the compared data can be calculated, and the explanatory variables that cause the biggest differentiation on the examined duration can be identified [43]:

$$
\hat{S}\left(t_{(f)}\right)=\hat{S}\left(t_{(f-1)}\right) \times \hat{P} r\left(T>t_{(f)} \mid T \geq t_{(f)}\right)
$$


The Cox proportional hazards model [44], given by Equation (4) below is a semiparametric method of duration analysis. Using the Cox model, it is possible to account for the simultaneous effect of different explanatory variables. The first part of the equation $h_{0}(t)$ is called the baseline hazard function and is not calculated by the model, hence it being a semi-parametric model. The second part of the equation describes the effect of the explanatory variables $(\boldsymbol{X})$ on the baseline hazard. The multiplier $\mathrm{b}$, called hazard ratio, is a crucial result of the Cox model, since it is the multiplier by which each explanatory variable affects the baseline hazard function. This means that, if $b$ is greater than 1 then then that value of the explanatory variable increases the probability of the event occurring. On the other hand, if $b$ is less than 1 , then that value of the explanatory variable reduces the probability of the event occurring. It is worth noting that when the effect of only one variable on duration is examined, the Cox proportional hazards model and the KaplanMeier method of survival analysis are practically equal [43,45]:

$$
h(t, X)=h_{0}(t) e^{\sum_{i=1}^{p} \beta_{i} X_{i}}
$$

Similar to other types of statistical analysis, we perform duration analysis under the assumption that apart from the explanatory variables, taken into consideration, all other parameters that affect the duration examined are considered equal [46]. The Cox proportional hazards model is widely used in duration analysis. Partially, the reason for this is that while there is no need to calculate the baseline hazard function, it is a robust, easily applied model and reliable hazard ratios, as well as survival or duration curves can be easily calculated.

The model is based on the assumption that the hazard ratios calculated are constant over time (proportional hazards assumption). It is important to thoroughly check that this case is met, as it is vital for the reliability of the outcome. In the event that the proportional hazards assumption's conditions are not met, a variation of the Cox proportional hazards model can be used. One variation is to stratify the model by the variable that does not meet the proportional hazards assumption and is called the stratified Cox Proportional Hazards model. In effect, this variation of the model calculates different models for the different values of the variable that does not meet the assumption. Another variation, is the extended Cox proportional hazards model, as it extends the model's capabilities, by calculating time-varying hazard ratios [43].

Duration analysis has been deemed as the most appropriate technique, since it can take into consideration all the above-mentioned information and is a statistical branch highly specialized in period analysis and has many advantages compared to more generic statistical tools. More specifically, duration analysis is an integrated tool that examines both the time until an event occurs at the same time as whether it occurs or not. Being able to incorporate that information in the analysis is crucial, since examining only the period until a set of events occurred (without taking into consideration observations for which the events did not occur) or only examining whether the events occurred or not (without taking into consideration the timing at which the occurred) would be heavily biased. Also, as it was mentioned, non-parametric duration models are very robust and are easily applied and interpreted. A disadvantage of duration analysis, and specifically of the Cox Proportional Hazards model, is the proportional hazards assumption. In the event of Hazards not being stable throughout time, one of the extended versions of the Proportional Hazards model would need to be utilized instead [43].

\subsection{Data}

For the purpose of the study, a questionnaire was designed containing 21 fully structured questions (none of the questions gave the option to the respondents to provide an open answer), divided into three sections. The questionnaire was anonymous and each of the sections was presented separately to the respondents who were randomly selected as being inhabitants of Greece for the majority of their life. Section A refers to the socioeconomic characteristics of the respondent, Section B pinpoints the respondent's mobility 
perceptions and needs and finally Section C identifies the private mobility milestones they have reached. The structure of the questionnaire and the data collected through it are also displayed in the flowchart of Figure 1.

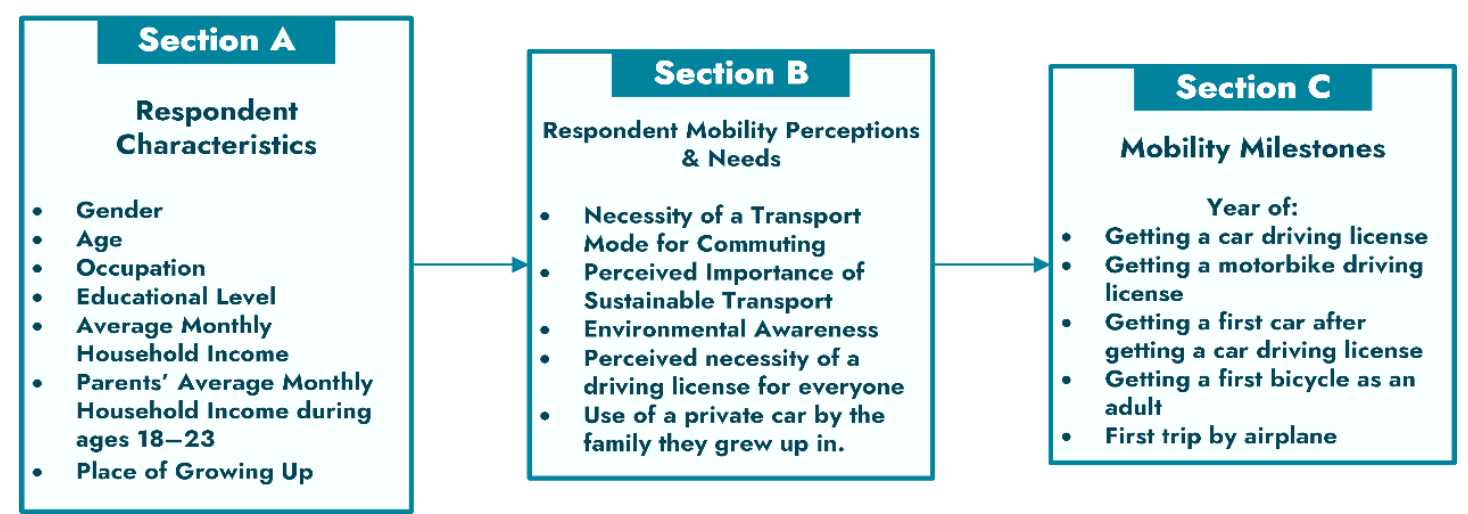

Figure 1. Survey design flowchart.

The data were collected via online questionnaires which were distributed via e-mail and social media chains in Greece. The aim of the data collection was to include people with a variety of socio-economic characteristics and in this respect the random sample selection method was chosen. Finally, 331 questionnaires were collected out of which 316 were considered valid and used further. Equation (1) presents the formula for the calculation of margin of error (MOE) which was calculated at 5.51, if we take into account a confidence level of $95 \%$ and total population size of 10,724,599 citizens, i.e., the current estimated population of Greece. Although the sample size may considered as small, the literature identifies numerous studies in Greece with even lower sample sizes [47,48]:

$$
M O E=z_{\gamma} \times \sqrt{\frac{\sigma^{2}}{n}}
$$

where $n$ is the sample size of the survey, equal to 331 cases, $z_{\gamma}$ : is the quantile (critical value) for confidence level of $95 \%$, equal to 1.96 and $\sigma$ is the standard deviation percentage (distribution) of the given answers, assuming a pessimistic value of $50 \%$.

The variables that were collected are presented in Table 1.

Table 1. Collected explanatory variables and time data.

\begin{tabular}{|c|c|c|c|c|}
\hline Variable Name & Levels & Percentage & Variable Type & Short Variable Description \\
\hline \multirow{2}{*}{$\operatorname{sex}$} & Male & $55.06 \%$ & \multirow{2}{*}{ Categorical } & \multirow{2}{*}{ Gender of the respondent } \\
\hline & Female & $44.96 \%$ & & \\
\hline birth & & & Ordinal & Year of birth of the respondent \\
\hline \multirow{8}{*}{ job } & Private Employee & $21.84 \%$ & \multirow{8}{*}{ Categorical } & \multirow{8}{*}{$\begin{array}{l}\text { Main area of employment during } \\
\text { the last decade }\end{array}$} \\
\hline & Public Servant & $14.87 \%$ & & \\
\hline & Freelancer & $14.24 \%$ & & \\
\hline & Unemployed & $5.38 \%$ & & \\
\hline & Household & $1.90 \%$ & & \\
\hline & Student & $36.71 \%$ & & \\
\hline & Pensioner & $3.48 \%$ & & \\
\hline & Other & $1.58 \%$ & & \\
\hline
\end{tabular}


Table 1. Cont.

\begin{tabular}{|c|c|c|c|c|}
\hline Variable Name & Levels & Percentage & Variable Type & Short Variable Description \\
\hline \multirow{6}{*}{ edu } & Primary School Graduate & $0.63 \%$ & \multirow{6}{*}{ Categorical } & \multirow{6}{*}{ Education level } \\
\hline & Secondary School Graduate & $0.00 \%$ & & \\
\hline & Highschool Graduate & $31.96 \%$ & & \\
\hline & Technical School Graduate & $7.28 \%$ & & \\
\hline & University Graduate & $32.59 \%$ & & \\
\hline & Graduate School & $27.54 \%$ & & \\
\hline \multirow{6}{*}{ funds } & 0-400 Euros & $5.38 \%$ & \multirow{6}{*}{ Ordinal } & \multirow{6}{*}{$\begin{array}{l}\text { Average monthly household } \\
\text { income during the last decade }\end{array}$} \\
\hline & 401-800 Euros & $12.97 \%$ & & \\
\hline & 801-1200 Euros & $27.53 \%$ & & \\
\hline & 1201-1600 Euros & $18.35 \%$ & & \\
\hline & 1601-2000 Euros & $16.47 \%$ & & \\
\hline & More than 2000 Euros & $19.30 \%$ & & \\
\hline \multirow{6}{*}{ par_funds } & 0-400 Euros & $5.70 \%$ & \multirow{6}{*}{ Ordinal } & \multirow{6}{*}{$\begin{array}{l}\text { Average monthly parents' } \\
\text { household income when the } \\
\text { respondent was 18-23 years old }\end{array}$} \\
\hline & 401-800 Euros & $12.34 \%$ & & \\
\hline & 801-1200 Euros & $23.73 \%$ & & \\
\hline & 1201-1600 Euros & $15.51 \%$ & & \\
\hline & 1601-2000 Euros & $16.14 \%$ & & \\
\hline & More than 2000 Euros & $26.58 \%$ & & \\
\hline \multirow{3}{*}{ grow } & City & $68.35 \%$ & \multirow{3}{*}{ Categorical } & \multirow{3}{*}{$\begin{array}{l}\text { Area in which the respondent } \\
\text { grew up }\end{array}$} \\
\hline & Town ${ }^{1}$ & $17.72 \%$ & & \\
\hline & Village $^{2}$ & $13.93 \%$ & & \\
\hline \multirow{3}{*}{ job_trsp } & Yes, on feet or by bicycle & $16.46 \%$ & \multirow{3}{*}{ Categorical } & \multirow{3}{*}{$\begin{array}{l}\text { Necessity of transportation for } \\
\text { commuting }\end{array}$} \\
\hline & Yes, with a mechanized vehicle & $39.87 \%$ & & \\
\hline & No & $43.67 \%$ & & \\
\hline \multirow{5}{*}{ sustain } & Very & $47.78 \%$ & \multirow{5}{*}{ Ordinal } & \multirow{5}{*}{$\begin{array}{l}\text { Importance of the sustainability of } \\
\text { the transport vehicle }\end{array}$} \\
\hline & Quite & $33.86 \%$ & & \\
\hline & Moderately & $12.03 \%$ & & \\
\hline & A Little & $5.06 \%$ & & \\
\hline & Not at all & $1.27 \%$ & & \\
\hline \multirow{5}{*}{ environ } & Very & $26.58 \%$ & \multirow{5}{*}{ Ordinal } & \multirow{5}{*}{ Environmental awareness } \\
\hline & Quite & $55.38 \%$ & & \\
\hline & Moderately & $12.34 \%$ & & \\
\hline & A Little & $5.38 \%$ & & \\
\hline & Not at all & $0.32 \%$ & & \\
\hline \multirow{5}{*}{ tech } & Very & $33.84 \%$ & \multirow{5}{*}{ Ordinal } & \multirow{5}{*}{$\begin{array}{l}\text { Respondent's familiarity with } \\
\text { technology }\end{array}$} \\
\hline & Quite & $47.12 \%$ & & \\
\hline & Moderately & $12.69 \%$ & & \\
\hline & A Little & $5.14 \%$ & & \\
\hline & Not at all & $1.21 \%$ & & \\
\hline
\end{tabular}


Table 1. Cont.

\begin{tabular}{|c|c|c|c|c|}
\hline Variable Name & Levels & Percentage & Variable Type & Short Variable Description \\
\hline \multirow{5}{*}{ lic_nec } & Very & $46.52 \%$ & \multirow{5}{*}{ Ordinal } & \multirow{5}{*}{$\begin{array}{c}\text { How necessary the respondent } \\
\text { feels is for everyone to get a } \\
\text { driving license }\end{array}$} \\
\hline & Quite & $34.81 \%$ & & \\
\hline & Moderately & $12.34 \%$ & & \\
\hline & A Little & $5.38 \%$ & & \\
\hline & Not at all & $0.95 \%$ & & \\
\hline car_lic & & & Categorical & $\begin{array}{c}\text { Year in which the respondent got a } \\
\text { car driving license }\end{array}$ \\
\hline \multirow{2}{*}{ fam_car } & Yes & $85.5 \%$ & \multirow{2}{*}{ Categorical } & \multirow{2}{*}{$\begin{array}{l}\text { Whether the respondent's family } \\
\text { used a car for transportation }\end{array}$} \\
\hline & No & $14.5 \%$ & & \\
\hline bike_lic & & & Ordinal & $\begin{array}{c}\text { Year in which the respondent got a } \\
\text { motorbike driving license }\end{array}$ \\
\hline first_car & & & Ordinal & $\begin{array}{l}\text { Year in which the respondent got } \\
\text { his first car }\end{array}$ \\
\hline first_bike & & & Ordinal & $\begin{array}{l}\text { Year in which the respondent got } \\
\text { his first bicycle as an adult }\end{array}$ \\
\hline first_plane & & & Ordinal & $\begin{array}{l}\text { Year in which the respondent first } \\
\text { travelled by airplane }\end{array}$ \\
\hline
\end{tabular}

1 “Town" was defined to the respondents as having a population of 10,000 citizens or less. ${ }^{2}$ "Village" was defined to the respondents as having a population of 2000 citizens or less.

The variables above were selected to examine whether they are affecting, to any significant degree, the time or age of occurrence of the five (5) examined mobility milestones. More specifically, the respondents' gender, age, income, employment status, necessity of motorized transportation for commuting, parents' transport behavior (use of a private car) and environmental attitude and sustainability of their mode of transport were included in our analysis as they were found by the literature to significantly affect one or more of the examined mobility milestones [1-16]. Further to those, we also added the respondents' education level, the income of their parents while they were 18-23 years old (because during those years they might have been financially dependent on their parents), their familiarity with technology and their perceived necessity for everyone to get a car driving license.

The effect of all of those variables on the occurrence of each mobility norm is examined and only the variables with a statistically significant effect are kept, according to the methodology presented below. Is the occurrence of mobility milestones affected by socioeconomic characteristics or other characteristics of one's life and in what ways? Are some of those characteristics more influential than others, by affecting multiple mobility milestones? Are there any intergenerational differences? For example, would the mobility habits of the family, someone grew up in, affect his own choices?

To analyze the occurrence of the five (5) mobility milestones, a time interval was calculated for each of them:

- The period from the age of 18 years old (the youngest possible age for getting a car driving license in Greece) until the age they got a car driving license.

- The period from the age of 16 years old (the youngest possible age for getting a motorbike driving license in Greece) until the age they got a motorbike driving license.

- The period from the age they got their car driving license until the age they got their first car.

- The period from the age 18 years old until the age they got their first bicycle as adults.

- The period from their birth until the age they traveled by airplane for the first time. 
For the respondents that had not completed the respective milestone, the ending point was the year of the study and those observations were considered censored for the purposes of the analysis.

The duration analysis was performed using the $\mathrm{R}$ programming language for statistical computing and graphics [49]. During the data configuration and the subsequent analysis the R packages dplyr, survival, survminer, flexsurv, ggplot2, ggthemes, MASS, car, plot3d, plot3drgl and forestmodel were used [50-60].

The duration analysis consisted of the following steps to ensure the accuracy of the constructed models.

(1) Definition of the examined period. Since the analyzed periods have different starting points we needed to clearly define each period's earliest possible starting point. i.e., the starting point of the period until getting a car driving license can't be earlier than the age of 18 years old.

(2) Definition and calculation of the necessary variables to perform duration analysis. This includes the calculation of the period that was set in the previous step as well as the definition of whether the observation is censored or not. i.e., if someone still hasn't obtained a car driving license when answering the survey, the observation is censored.

(3) Non-parametric duration analysis using the Kaplan-Meier method.

(4) Test of all the explanatory variables' effect on duration, with the use of the log-rank test. Variables with a log-rank test $p$-value less or equal to 0.05 will be used in the next step.

(5) Plot of survival curves for explanatory variables with significant effect on duration, as they were found in the previous step.

(6) Variable selection for the Cox Proportional Hazards Model, using a step by step selection method, as it was described by Collet [61].

(7) Correlation check of the selected variables to avoid multicollinearity.

(8) Check the Proportional Hazards Assumption for a simple Cox model or an extended or stratified Cox model if the assumption is not satisfied at first.

(9) Build a Cox Proportional Hazards Model, using the variables selected in the steps above.

(10) Model validation using the Cox-Snell and Deviance residuals for each model.

The conservative rule of 10 outcome events per predictor variable applies for every one of the models that were constructed are presented in the following chapter [62].

\section{Results}

In this chapter the duration analysis of the data is performed. The analysis of each event will be examined next.

\subsection{Duration Analysis of the Age at Which Someone Gets Their Car Driving License}

In Greece car driving licenses can be acquired only after the completion of one's 18th year [63]. Student drivers are tutored theoretically and practically in private driving schools and, before getting a driving license, they can legally drive only when accompanied by a certified professional instructor. The driving lessons' minimum cost is about $700 €$ and can increase significantly if the learner needs more driving lessons than the minimum number required. Most of the population goes through this procedure regardless of whether they will regularly drive a private car in the immediate future. Knowing which factors affect the age of getting a car driving license can be of great importance for future transport planning.

Figure 2 shows the survival curve and its 95\% confidence intervals, as it was calculated via the Kaplan-Meier method for the whole sample. As can be seen, the probability of getting a car driving license increases significantly during the first 10 years after the age of 18 years. By the age of 40 years, the probability of getting a car driving license was more than $90 \%$. It is obvious that getting a car driving license seemed to be a priority for most of the sample and the durations are short on average. There is no survival time for a 
$0 \%$ probability of not getting a car driving license, as there were respondents that had not yet gotten a driving license in older ages in the sample.

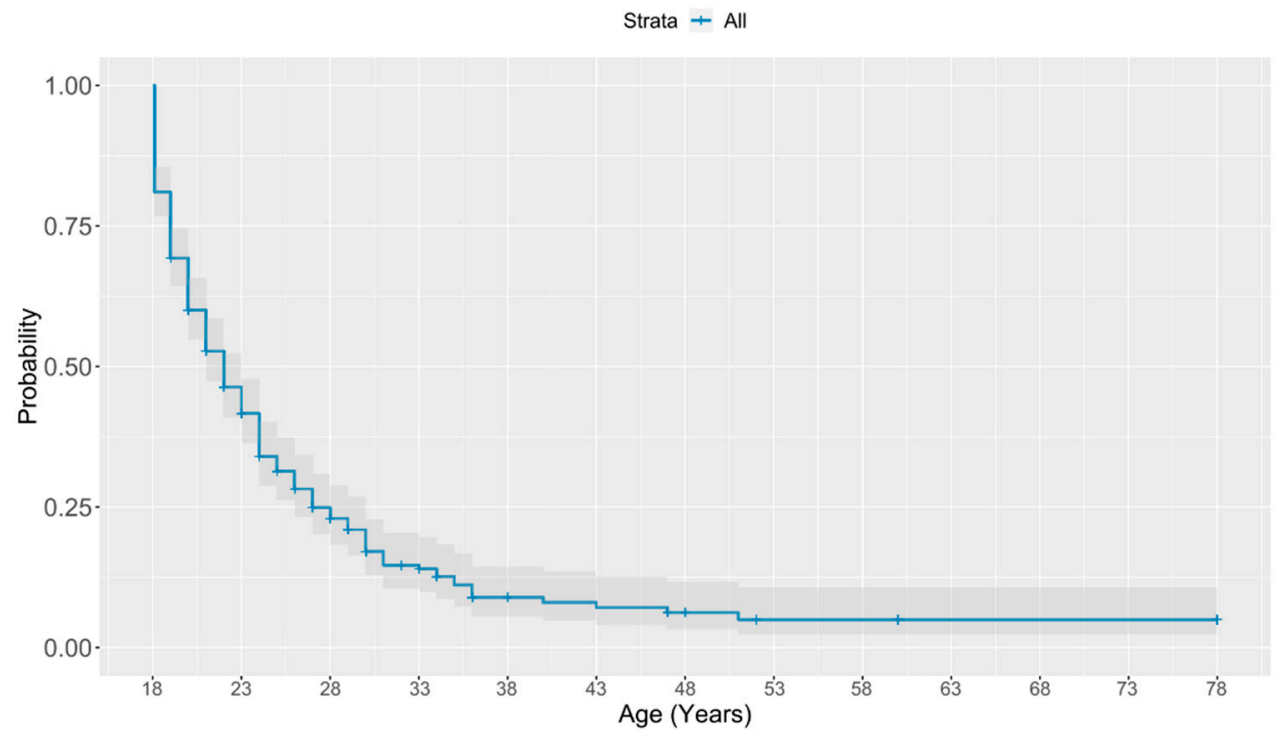

Figure 2. Kaplan-Meier Survival Curve of the probability of not having gotten a car driving license.

The plots in Figure 3 show the stratified survival curves for the explanatory variables that appeared to greatly affect the age of getting a car driving license in the log rank test, as they were calculated via the Kaplan-Meier method. All of them display significant difference in the probability of getting a car driving license over time.

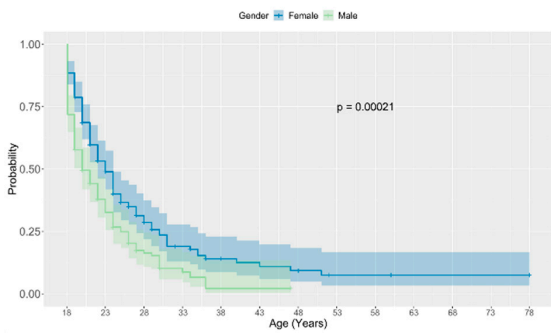

(a)

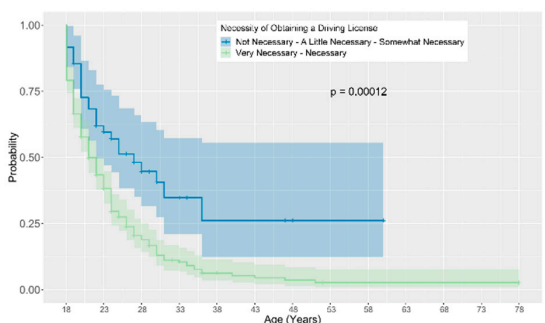

(d)

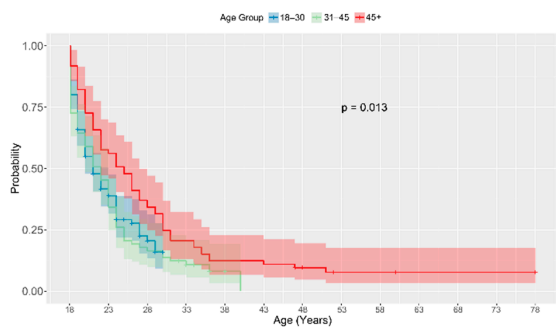

(b)

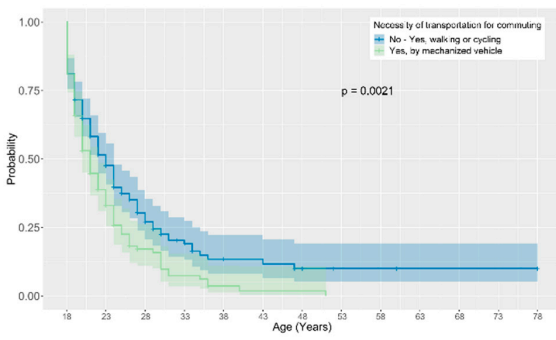

(e)

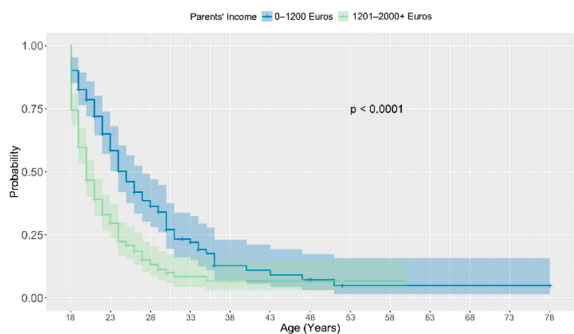

(c)

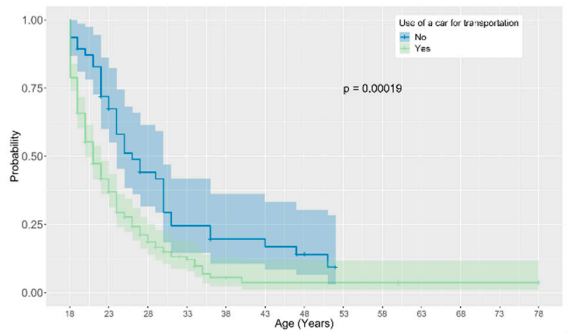

(f)

Figure 3. Survival Curves of the age of getting a car driving license stratified by: (a) Gender; (b) Age Group; (c) Parents' Income at age 18-23; (d) perceived necessity of having a driving license; (e) necessity of a transport mode for commuting; (f) the use of a car within the family.

Out of them, five (5) were found statistically significant and were included in the Cox Proportional Hazards model that was fitted. The "parents' income" variable did not meet the requirements of the hazard being proportional with the elapsed time of the proportional hazards assumption. To remedy that, an extended Cox model was built. In the extended 
Cox model, the hazard ratio of the explanatory variables doesn't remain constant, but its values can change through time. Towards that end, two variables that measure the parent's income were introduced in the model. The "parents' funds 1" variable that measures the effect of the parents' income during the first two (2) years after the age of 18 years old and the "parents' funds 2" variable, that measures the effect of the parents' income during the rest of their lifetime. The results of the Cox model are shown in the forest diagram of Figure 4 .

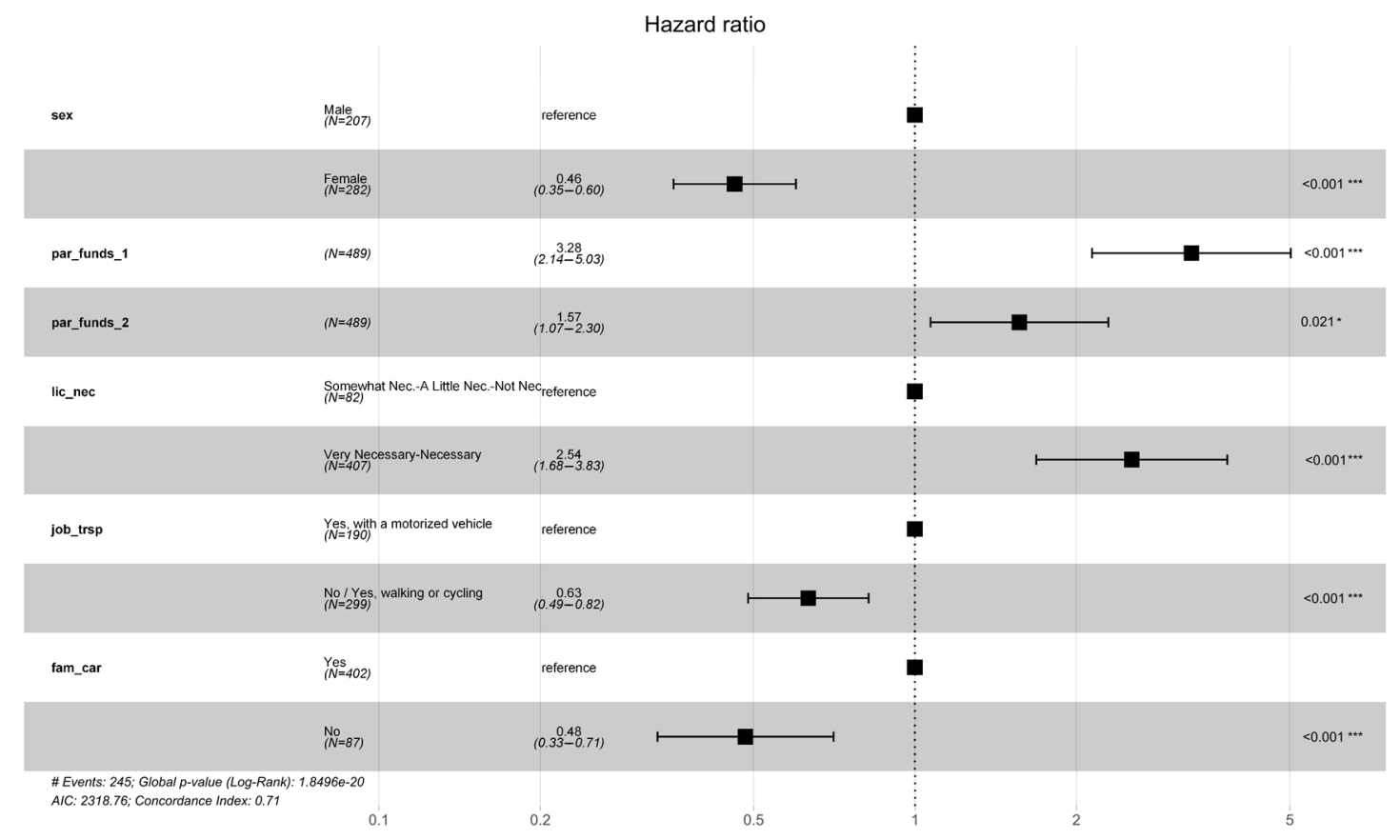

Figure 4. Cox Proportional Hazards Model Forest Plot for getting a car driving license (the number of observations in the forest plot is larger than 316 because of the manipulation that was performed in the dataset to create the extended Cox model).

As can be seen in the survival curve of Figure 3a, men have significantly higher chances of getting a car driving license over time compared to women, and that difference is especially prominent at the age of 18 years. This is quantified by the 0.46 hazard ratio that was calculated in the model (less than half the chance of getting a license over time for women compared to men). Figure $3 b$ shows that there is a significant difference in the probability of getting a car driving license between different age groups. Specifically, respondents that were over 45 years old seemed to have a higher chance of getting a license throughout their lifetime. This could in part be due to the effects of the economic crisis that most heavily affected younger generations during their productive and younger years. A possible improvement of the economy in the future could lead to younger generations getting car driving licenses in older ages. The survival curves of Figure $3 c$ show that respondents, whose parents had higher income during their first adult years, had significantly higher chances of getting a car driving license, especially during ages 18-29. The difference majorly drops in older ages. This is also showcased by the hazard ratios for the Parents' Funds variables. The first has a hazard ratio of 3.28, showing that for ages 18-20 those with parents with higher incomes have more than triple the chance of getting a license. On the other hand, the effect of the parents' income greatly diminishes for older ages, as the 1.57 hazard ratio of the par_funds_2 variable shows. In modern western societies, it is common for young adults to be financially dependent or partially dependent on their parents, especially if they pursue a university degree. Getting a car driving license can be a heavy expenditure for lower incomes and higher parents' income seems to greatly affect the age at which someone gets a car driving license. Furthermore, it is worth mentioning that while the age group was found to have a statistically significant effect on its own, it 
was not fond statistically significant in tandem with the effect of the other variables and was not included in the Cox Proportional Hazards model. This could possible showcase that other factors such as a their parents' income at younger ages similarly affected the time of getting a car driving license throughout generations. Figure $3 \mathrm{~d}$ shows that the perceived necessity of having a car driving license also increases the probability of getting a car driving license, something also reflected by the hazard ratio of 2.54 . The survival curves of Figure 3e show that the group of respondents that don't currently require a motor vehicle for their commuting are much less likely to have gotten a car driving license, something that is also displayed by the hazard ratio of 0.63 . Professional needs appear to be a strong incentive towards getting a car driving license. Finally, Figure $3 \mathrm{f}$ shows that respondents that grew up in a family that did not use a private car for transport were much less likely to get a car driving license sooner in their lives, something that is also shown by the hazard ratio of 0.48 . Family habits affect later generations' transport habits and the environment someone grows up in has the potential to significantly affect their choices later in life.

\subsection{Duration Analysis of the Interval from Getting a Car Driving License until Getting a First Private Car}

Buying a car is a choice affected by many factors. Choosing to buy a used or new car, has been successfully linked with a variety of factors, like income, employment status, the area of residence and more. Exploring the factors that affect the interval from getting a car driving license until getting a car is of particular interest [64].

As can be observed from the survival curve of Figure 5, the chance of someone getting their first car, increases steeply at time 0 (meaning at the time of getting a car driving license). Then the chance increases moderately for 10 years and at an even lower rate after that. About 26 years after getting a car driving license the chance of having a car approaches $100 \%$, meaning that the overwhelming majority of the sample got a personal vehicle at some point after getting a car driving license.

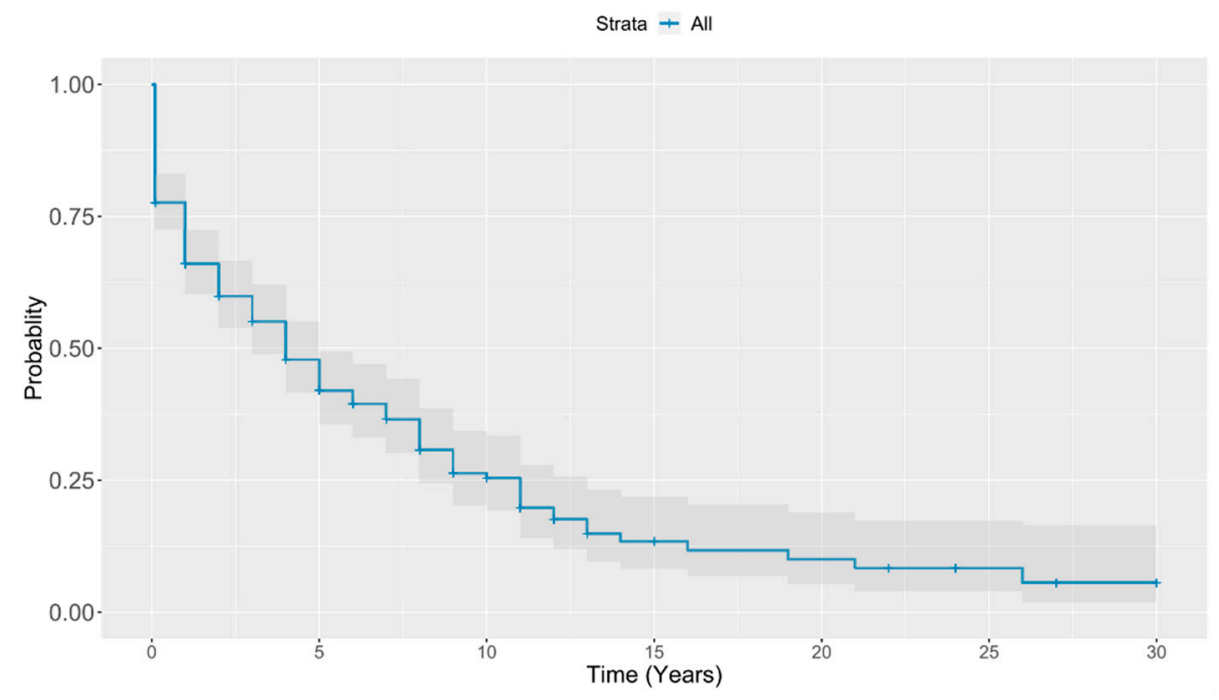

Figure 5. Kaplan-Meier Survival curve of the probability of not having gotten a first car with time after getting a car driving license.

The plots in Figure 6 show the stratified survival curves for the explanatory variables that appeared to greatly affect the time interval from getting a car driving license until getting a first car in the log rank test, as they were calculated via the Kaplan-Meier method. All of them display significant difference in the probability of getting a car.

The explanatory variables above were found statistically significant and were included in the Cox Proportional Hazards model that was built, and can be seen in the forest plot of Figure 7. 


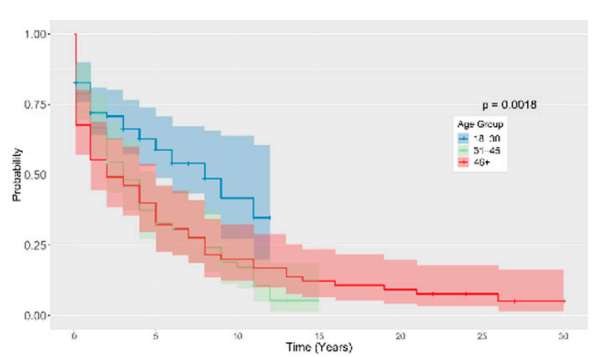

(a)

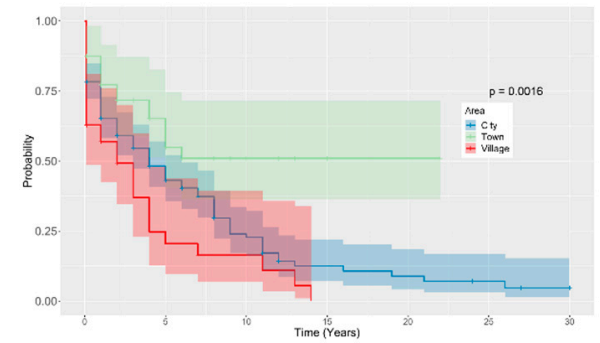

(b)

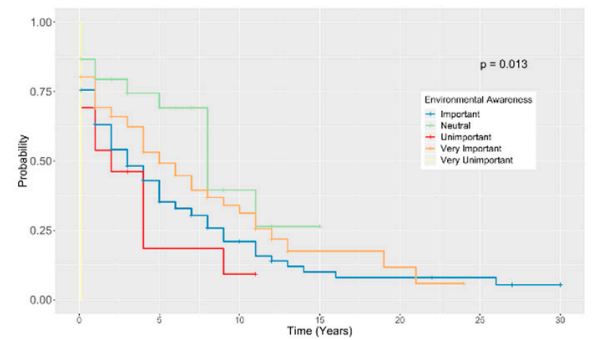

(c)

Figure 6. Survival Curves of the time interval from getting a car driving license until getting a car stratified by: (a) Age Group; (b) The Area in which someone grew up; (c) Environmental Awarenes.

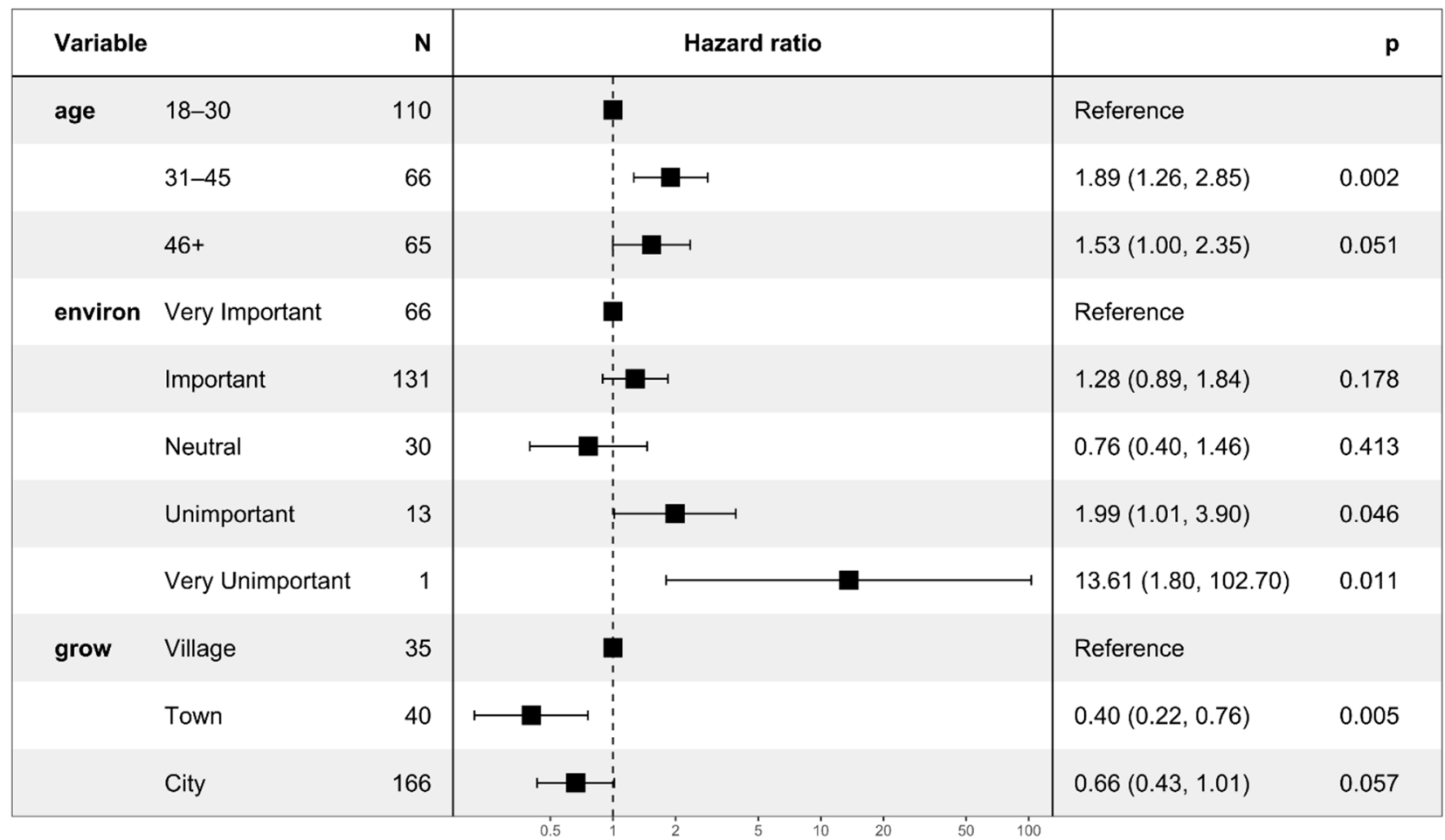

Figure 7. Cox Proportional Hazards Model Forest plot for getting a first car.

According to the survival curves of Figure 6a, respondents that were in the 18-30 age group have significantly lower chances of getting their first car over the years compared to older respondents. This is also displayed by the older age groups' hazard ratios of 1.89 and 1.53. In recent years there have been multiple reports that younger people tend to buy fewer cars than they used to on average. Possible reasons for that are a preference towards service-based mobility or delaying buying a car until older ages [65]. Another possible explanation is the effect of the economic crisis, that affected the purchasing capacity of younger generations more during their productive years. Furthermore, as can be seen in the survival curves of Figure 6b, the place a respondent grew up seems to affect how fast after getting a driving license they got their first car. Respondents that grew up in villages seem to get their first car faster after getting a car driving license. The hazard ratios of 0.40 and 0.66 for towns and cities also are in accordance with that. One possible explanation is that respondents that grew up in villages had a more urgent need for reliable private transportation, as villages in Greece are more isolated and rural areas [66,67]. On the other hand, cities and towns offer public transport services that render the need of purchasing a private vehicle much less immediate. The survival curves of Figure $6 \mathrm{c}$ show that respondents, that are less environmentally aware, are more like to get a car faster after 
getting a car driving license. This becomes even more prominent by the hazard ratios of 1.99 and 13.61, showing a clear trend of more environmentally aware people getting a car later on average.

\subsection{Duration Analysis of the Age at Which Someone Their Motorbike Driving License}

In Greece motorbike driving licenses can only be acquired after the completion of one's 16th year. On the other hand, bigger motorcycles with more cubic capacity (more than $400 \mathrm{cc}$ ) can only be acquired after the completion of one's 24th year [63]. Two-wheeled motor vehicles have certain advantages like circumventing congestion and are often preferred over automobiles especially for specific usage [68].

In this case there was a large number of censored observations in the data (more than $50 \%$ of the observations), meaning that more than half of the sample had not obtained a motorcycle driving license. As can be observed in Figure 8, the chance of getting a motorcycle driving license slowly increases during the first years after the age of 16 years, and then increases even slower. This is an expected outcome, as motorcycles are a vehicle with much smaller target group than cars. Also, it can be noted that the chance increases less in older ages compared to the curve for the car driving license.

Strata + All

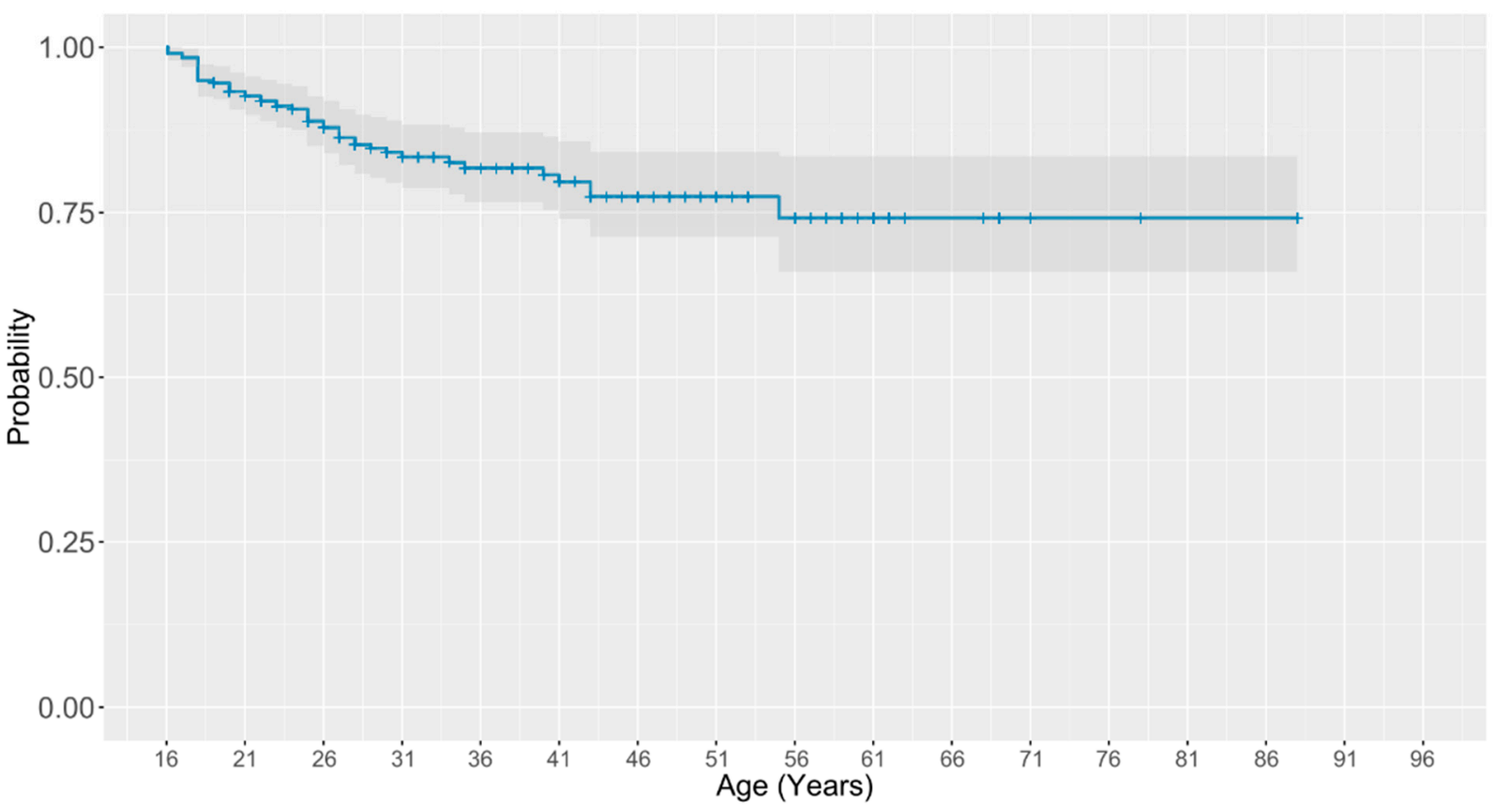

Figure 8. Kaplan-Meier Survival Curve of the probability of not having gotten a motorbike driving license.

The plots in Figure 9 show the stratified survival curves for the explanatory variables that appeared to greatly affect the age at which a respondent got a motorcycle driving license in the log rank test, as they were calculated via the Kaplan-Meier method.

Out of these explanatory variables three (3) were found statistically significant and were included in the Cox Proportional Hazards model that was built and can be seen in the forest diagram of Figure 10.

According to the survival curves of Figure 9a, men appear to have a significantly higher probability of getting a motorbike driving license over the years, while women's probability increases at a much slower rate. More specifically, male respondents were more than 4.5 times more likely to get a motorbike driving license, according to the hazard ratio of the Cox model (4.56). Additionally, based on the curves of Figure $9 \mathrm{~b}$ respondents, whose parents had a lower income during their first adult years, have a higher chance of getting a motorbike driving license over the years. More specifically, that chance increases more steeply until the age of 40 years old. That result makes sense, as a car driving license is more expensive to obtain 
and a car a more expensive vehicle to maintain and use. It is worth noting that this is the opposite of the effect parents' income was found to have on getting a car driving license. It can be indicative of lower incomes groups covering their needs with a more affordable option. Figure $9 \mathrm{c}$ shows that needing a motorized vehicle for commuting significantly increases the chances of getting a motorbike driving license sooner. That is in accordance with the 2.67 hazard ratio output of the Cox model. Finally, as can be seen in Figure 9d, the perceived importance of sustainable transportation heavily affects the chances of getting a motorbike driving license. The hazard ratio of 0.47 that was calculated, also shows that respondents that think sustainable transportation is "Very Important" or "Important" are much less likely to get a motorbike driving license over the years.

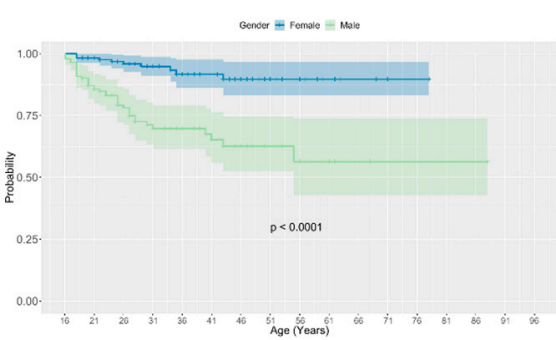

(a)

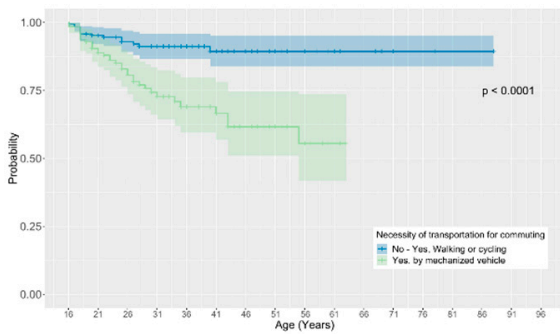

(c)

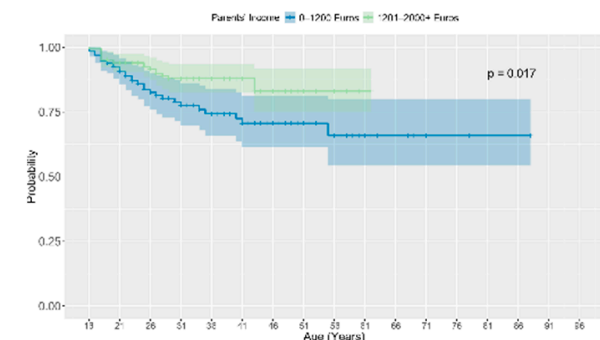

(b)

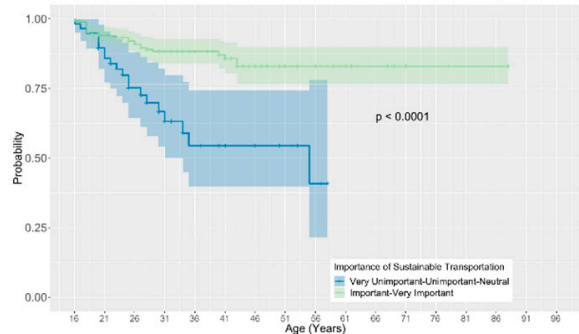

(d)

Figure 9. Survival Curves of the age of getting a motorcycle driving license stratified by: (a) Gender; (b) Parents' Income at ages 18-23; (c) The necessity of a transport mode for commuting; (d) The perceived importance of sustainable transportation.

\begin{tabular}{|c|c|c|c|c|c|}
\hline Variable & & $\mathbf{N}$ & Hazard ratio & & p \\
\hline sex & Female & 174 & 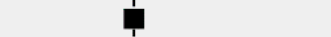 & Reference & \\
\hline & Male & 142 & $\longmapsto-1$ & $4.56(2.26,9.19)$ & $<0.001$ \\
\hline sustain & Neutral - Unimportant - Very Unimportant & 58 & [ & Reference & \\
\hline & Very Important-Important & 258 & $\longmapsto$ & $0.47(0.26,0.84)$ & 0.011 \\
\hline job_trsp & No / Yes, walking or cycling & 190 & $\boldsymbol{\varphi}$ & Reference & \\
\hline & Yes, with a motorized vehicle & 126 & $\longmapsto$ & $2.67(1.44,4.98)$ & 0.002 \\
\hline
\end{tabular}

Figure 10. Cox Proportional Hazards Mode forest plot for getting a motorcycle driving license. 


\subsection{Duration Analysis of the Age at Which Adults Get Their First Bicycle}

Bicycle usage encompasses multiple advantages compared to other means of transport, for the traveller as well as for society. For this reason, and particularly during recent years, many cities try to offer incentives to promote bicycle transport. There have been many attempts to pinpoint the factors that affect bicycle usage for transport. Some examples are correlations between bicycle usage and related infrastructure, land use patterns, topographical factors such as altitude difference, socio-economic characteristics of the general population of an area, attitudes towards cycling, the attitude of the social environment towards cycling, the safety cyclists perceive during their transport, duration of an average bicycle route and more [69-72]. Given that bicycle usage for transport is very low in Greece compared to other European countries [73], examining the factors that affect bicycle acquisitions from adults is particularly interesting. One of the reasons is the low level of service of the Greek infrastructure that cyclists face in terms of safety and comfort [74], which also has a negative impact on the bicycle sales in Greece per inhabitant compared to other European countries [75].

As can be seen in the survival curve of Figure 11, the chance of a respondent getting their first bicycle after the age of 18 years, increases significantly at the age of 18 years old (meaning many people bought bicycles at the age of 18 years). Then it increases moderately until about the age of 45 , when the increase diminishes. Overall, the chance of having obtained a bicycle is about $50 \%$ at the age of 50 years.

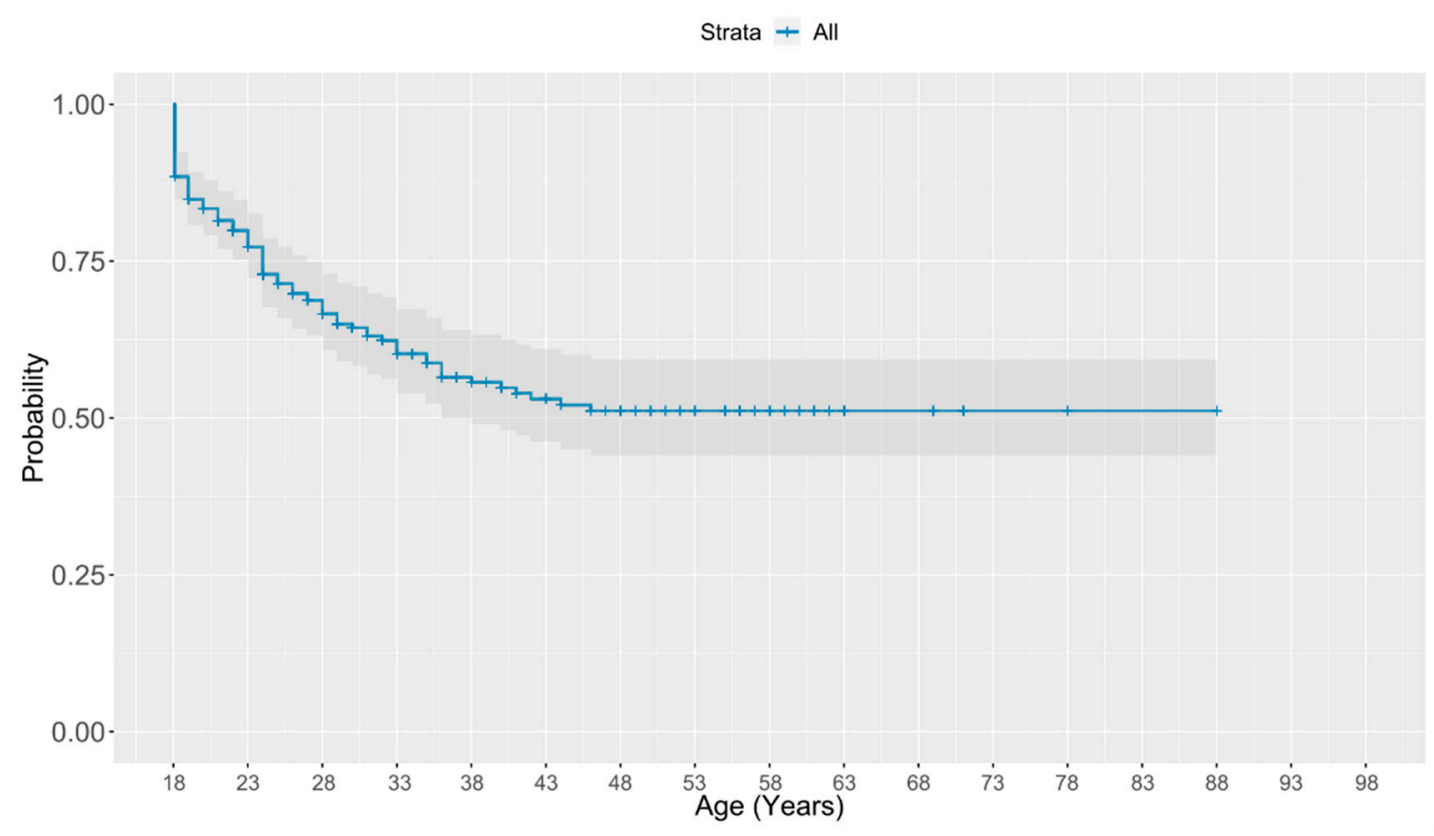

Figure 11. Kaplan-Meier Survival Curve of the probability of not having gotten a bicycle as an adult.

The plots in Figure 12 show the stratified survival curves for the explanatory variables that appeared to greatly affect the age that a respondent got their first bicycle as an adult in the log rank test, as they were calculated via the Kaplan-Meier method.

Those two (2) explanatory variables with the addition of the area the respondent grew up in, were found statistically significant and were included in the Cox Proportional Hazards model that was built and can be seen in the forest diagram of Figure 13. 


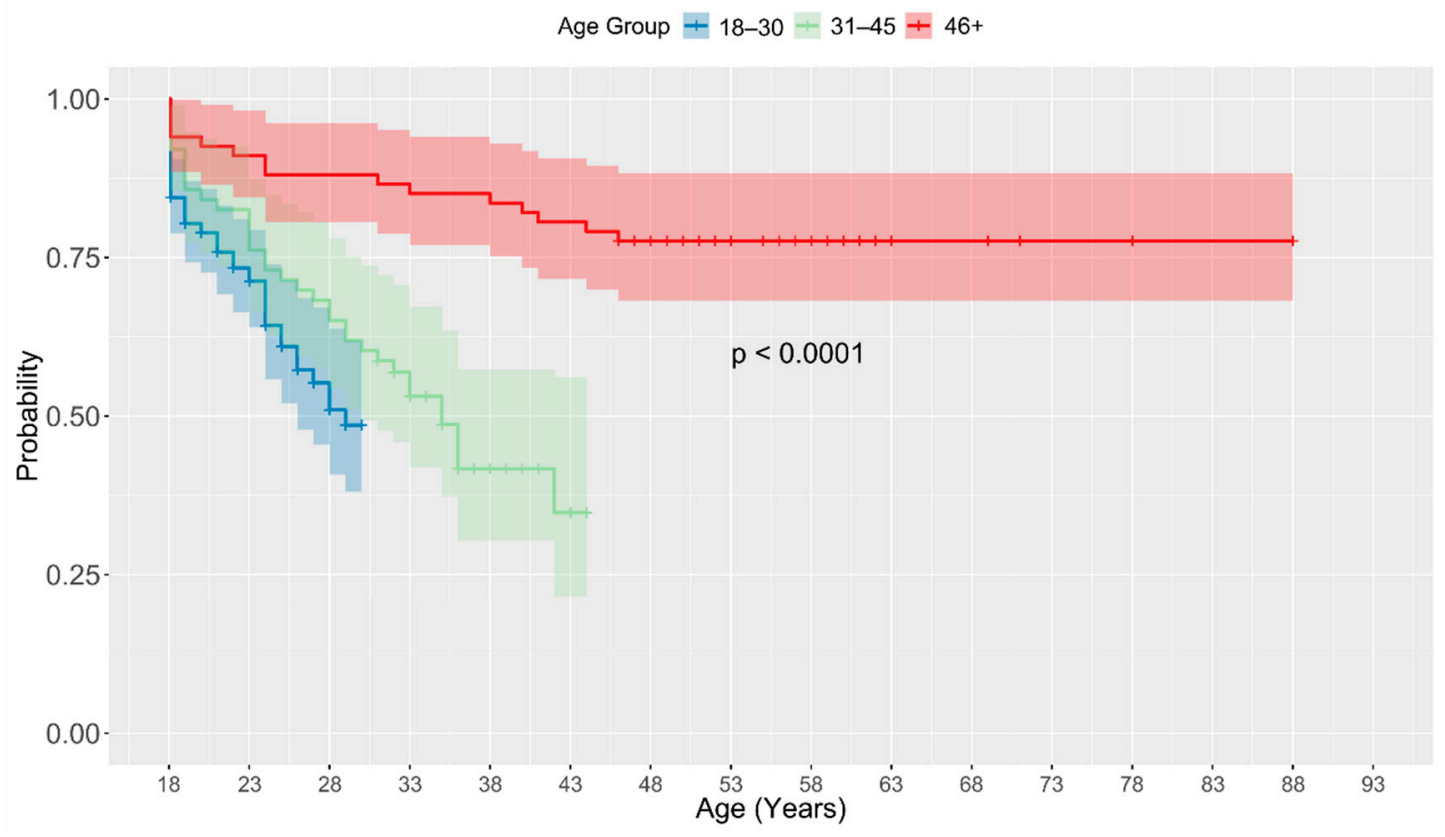

(a)

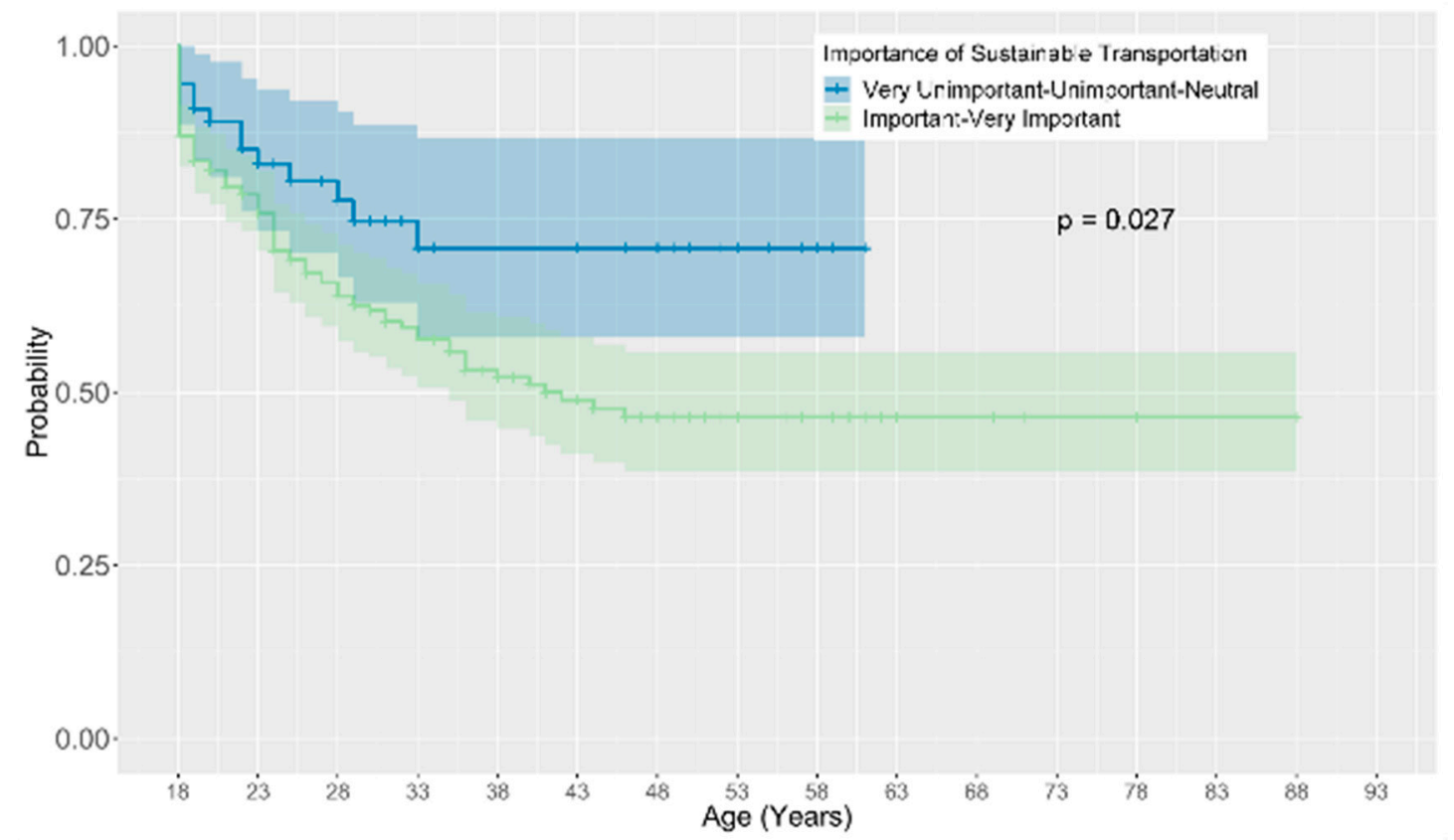

(b)

Figure 12. Survival Curves of the age of getting a first bicycle stratified by: (a) Age Group; (b) The perceived importance of sustainable transportation. 


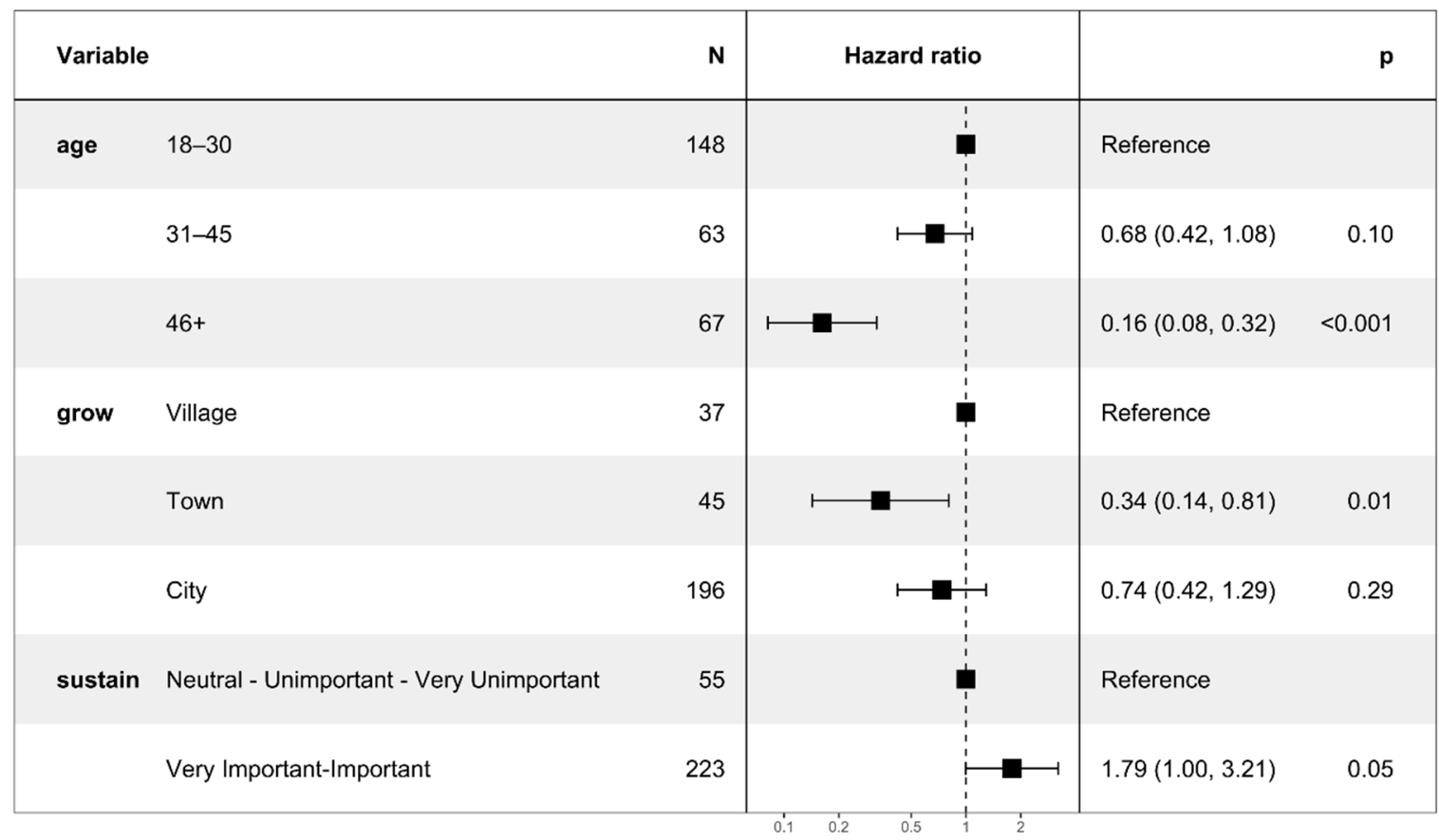

Figure 13. Cox Proportional Hazards Mode forest plot for getting a first bicycle as an adult.

The survival curves of Figure 12a show that respondents in the " $46+$ " age group have a very small chance of getting a bicycle throughout their lifetimes compared to younger

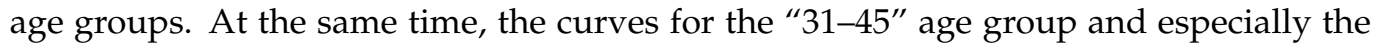
"18-30" age group show that the chance of getting a bicycle rapidly increases throughout their lifetimes. The hazard ratios of 0.68 and 0.16 for the " $31-45^{\prime \prime}$ and " $46+$ " age groups are also in accordance with those results and show the chances of having gotten a bicycle as adults decrease with age. Those results show an increasing trend of younger generations shifting towards preferring sustainable, human-powered transport modes. Green directives and sustainable mobility policies are a mechanism that could have made this change possible [76]. Apart from that, the economic crisis could have also affected the purchasing capacity of younger generations and pushed them towards opting for less expensive private modes of transport, such as the bicycle. Based on the survival curves of Figure 12b, respondents that believe sustainable transport is important have much greater chances of getting a bicycle earlier as adults, compared to other respondents. That is also shown by the hazard ratio of 1.79 for those respondents. It is noteworthy that while the chance of getting a bicycle steeply rises during the first years of adulthood, it also continues to rise throughout their lifetimes. Having a consciously sustainable attitude towards traveling appears to be a major factor towards bicycle purchase throughout one's lifetime. Finally, the hazard ratios of 0.34 and 0.74 for respondents that grew up in towns and cities respectively show that they are much less likely to get a bicycle as adults compared to respondents that grew up in villages. A possible explanation is that those whole grew up in villages had a bigger need of having a reliable private transport vehicle, due to living in remote areas, that are less frequently covered by public transport [66,67]. On the other hand, research has shown that bicycle usage has been mostly linked with shorter trip distances and rural areas are usually characterized by longer trips. $[77,78]$

\subsection{Duration Analysis of the Age at Which Someone Travels by Airplane for the First Time}

In recent years, air transport is becoming more and more common, cheap and frequent. Due to globalization, privatization and competitiveness between air carriers, air transport is more affordable than ever, and demand keeps rising. Flight demand doubles approximately every 15 years [16]. 
As can be seen by the survival curve in Figure 14, the chance of having travelled by airplane increases moderately fast on average. The gradient of the curve becomes steeper during the ages of 17-25, meaning that the chance of having travelled by an airplane increases at a faster rate during those years. The chance of having travelled by airplane approaches $100 \%$ at the age of 52 years.

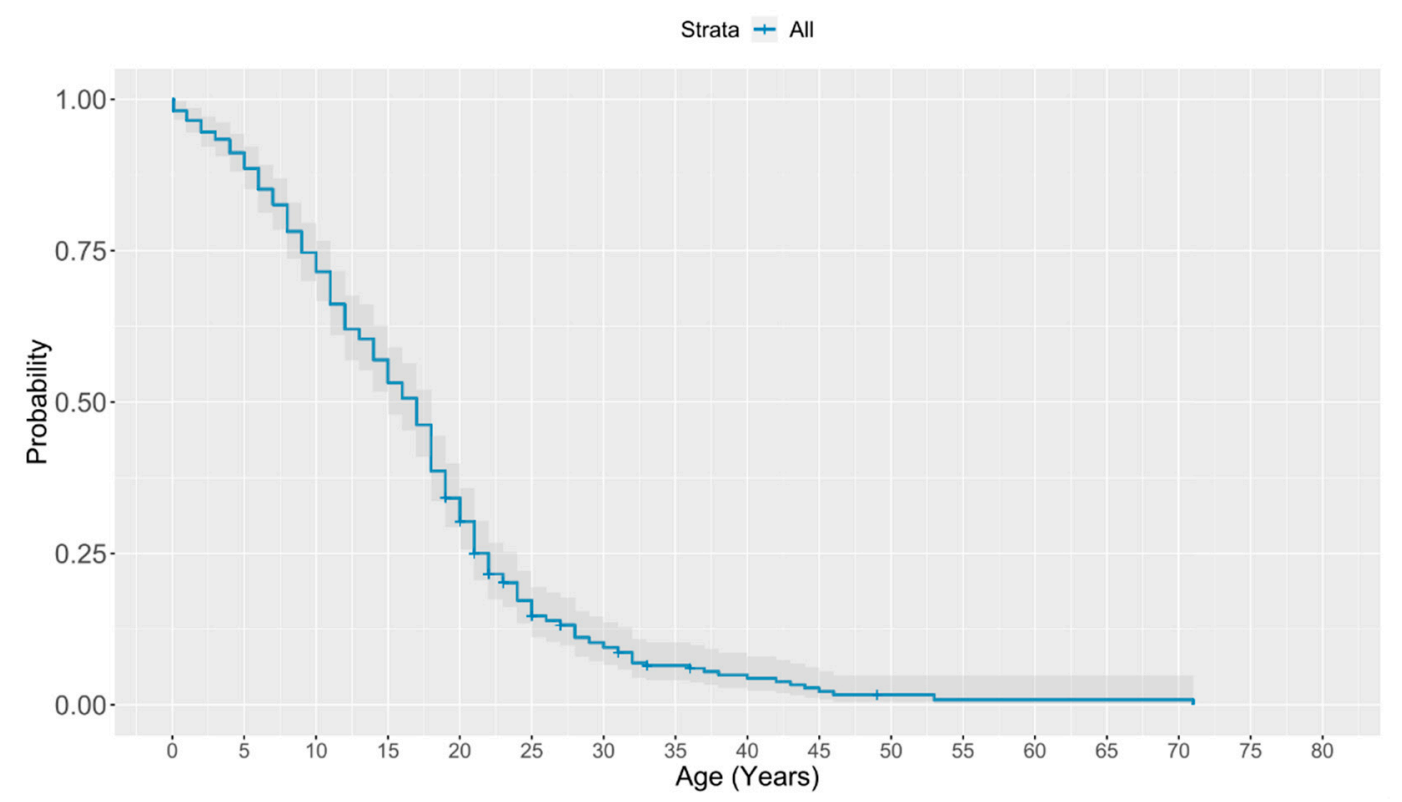

Figure 14. Kaplan-Meier Survival Curve of the probability of not having travelled by airplane for the first time.

The plots in Figure 15 show the stratified survival curves for the explanatory variables that appeared to greatly affect the age that a respondent first travelled by airplane in the log rank test, as they were calculated via the Kaplan-Meier method.

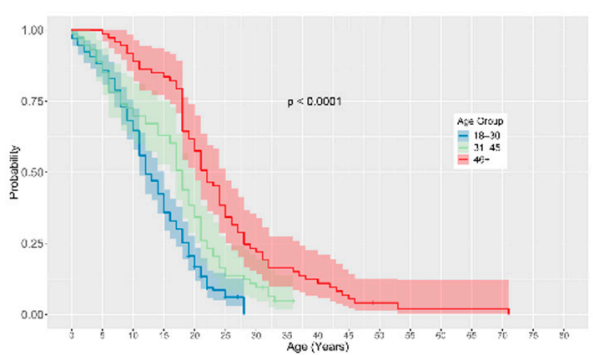

(a)

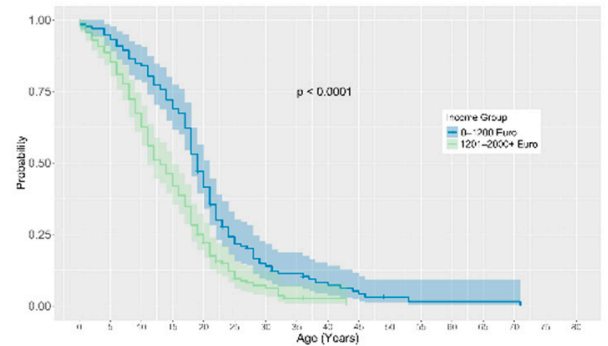

(b)

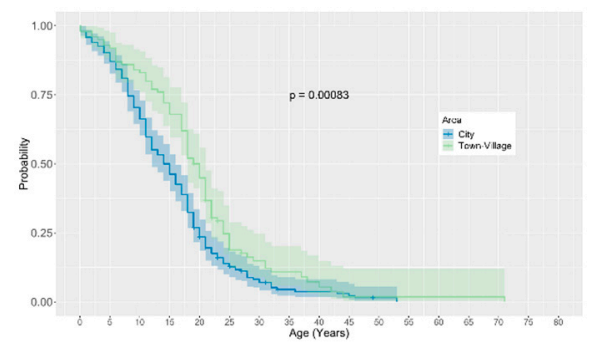

(c)

Figure 15. Survival Curves of the age of travelling by airplane for the first time stratified by: (a) Age Group; (b) Parents' Income at ages 18-23; (c) The area in which someone grew up.

From the explanatory variables shown above, all 3 were found statistically significant and could be included in the Cox Proportional Hazards Model. Because the variable for parent's income violated the proportional hazards assumption (that the hazard generated by the variable remains relatively constant through time) it could not be included in the simple form of the Cox model. In this instance, an extended Cox Model could not be built, due to the variable's variance with time, so a Stratified Cox Model was built instead. This model cannot calculate a hazard ratio for the parents' income variable, but it is possible to show the difference between its values graphically. The hazard ratios for the rest of the variables can be seen in the forest plot of Figure 16 and the graphical representation of the levels for the "Parents' Income" variable are shown in Figure 17. 


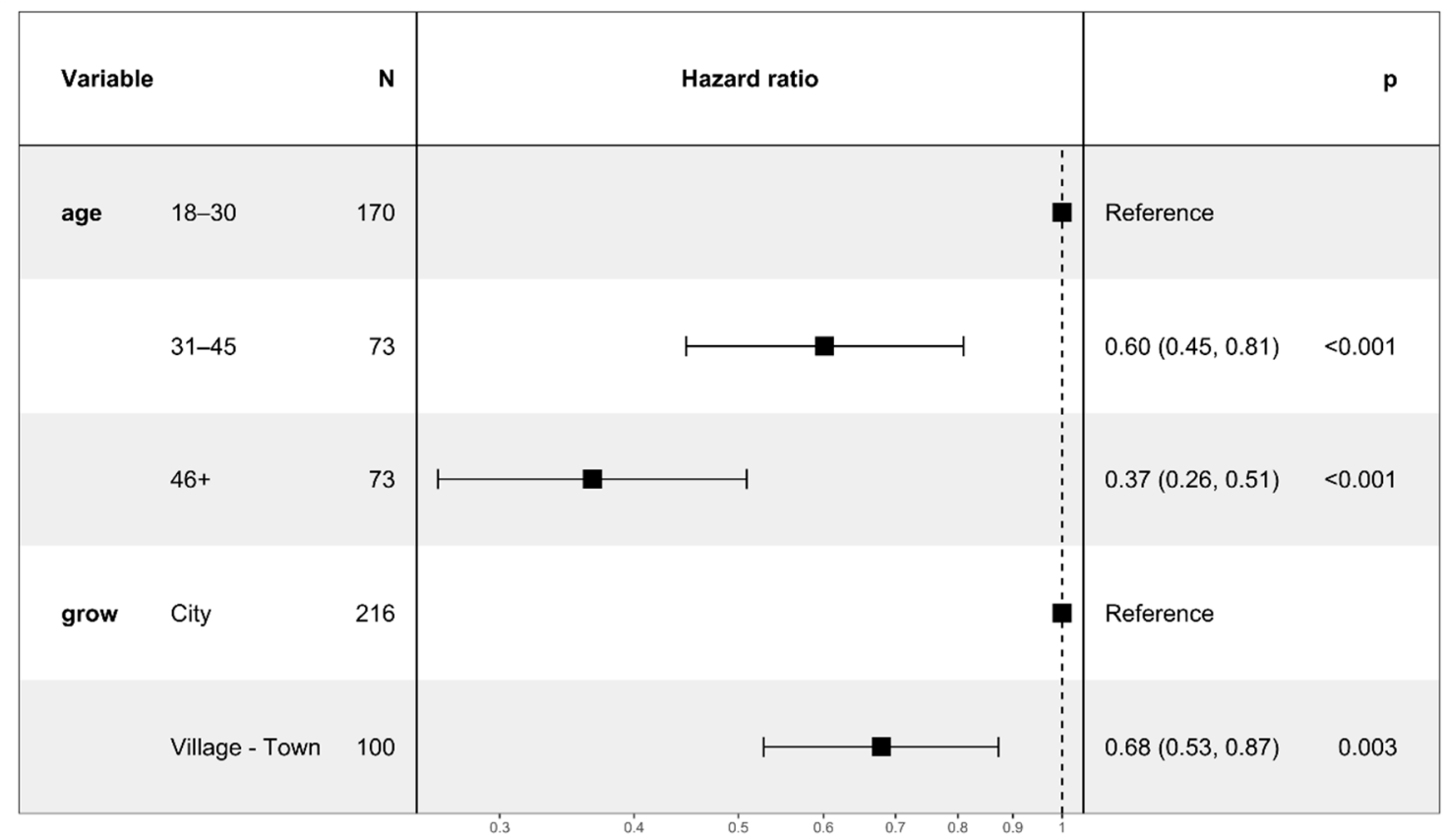

Figure 16. Cox Proportional Hazards Mode forest plot for travelling by airplane for the first time.

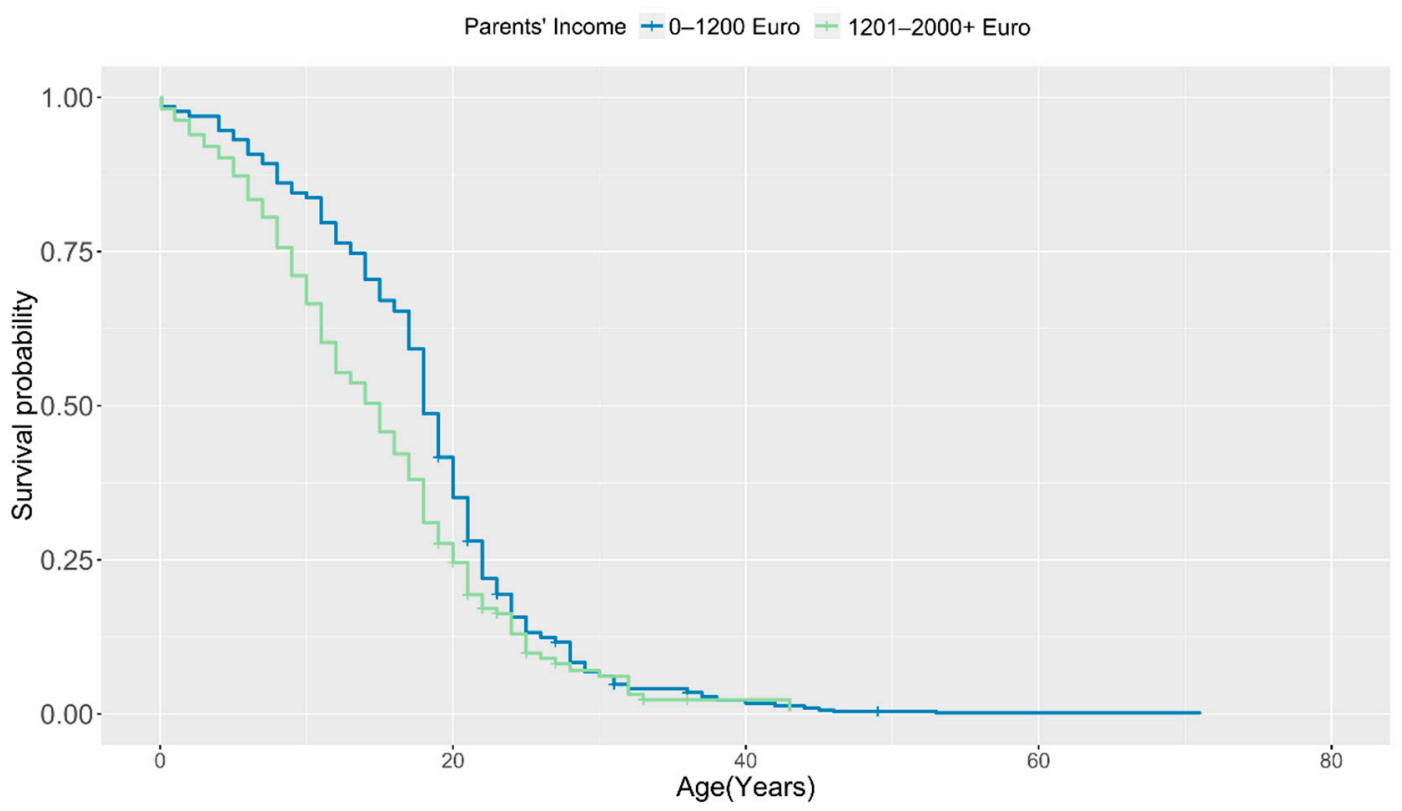

Figure 17. Cox Proportional Hazards Model results of the probability of not having travelling by airplane for the first time stratified by Parents' Income.

According to the survival curves of Figure 15a, respondents of younger generations, have considerably higher chances of traveling by airplane over the years. While all three age groups ("18-30", "31-45" and " $46+$ ") approach $100 \%$ of having traveled by airplane throughout their lives, the younger age groups reach this point sooner. The hazard ratios of 0.60 and 0.37 for the age groups " $31-45$ " and " $46+$ " respectively are aligned with those results. Those differences are indicative of the continuously higher demand for air travel, due to airfares becoming more affordable [16]. The survival curves of Figure 15b show that the respondents whose families had higher incomes have significantly higher chances of having traveled by airplane over the years. It is worth noting that the chance of having traveled for the respondents whose parents had lower incomes increases more rapidly after the age of 18 years. Those differences are also displayed in the difference between lower 
and higher incomes, as they were predicted by the Cox Proportional Hazards model and were shown in Figure 17. Finally, according to the survival plots of Figure 15c, respondents that grew up in cities have higher chances of having traveled by airplane over the years. This difference appears to be more intent during the ages 10-20 and less intent later on. The hazard ratio of 0.68 for growing up in a village or town is in accordance with that. A possible explanation is that due to the higher density of business and economic activities in the city, families that live in the cities are more likely to take trips earlier on.

\subsection{Mutual Evolution of Mobility Milestones}

Apart from examining the temporal appearance of each one of those milestones separately, it is possible to examine the way two of those milestones appear in the duration of a lifetime, with regards to each other. This fact actually represents the real-life phenomena where milestones, preferences and motives are built through complex interrelated effects.

For this example, we chose to examine how the chance of getting a first car is visualized with regards to the chance of getting a car driving license. To achieve that, there was need to fit a new model for the time at which one obtains a new car, since the previous model that was developed was predicting the time, starting from when someone obtains a car driving license. So, a new model for getting a first car was fitted, predicting the time starting from the age of 18 . This model, together with the one predicting the time from the age of 18 until getting a car driving license is illustrated in Figure 18.

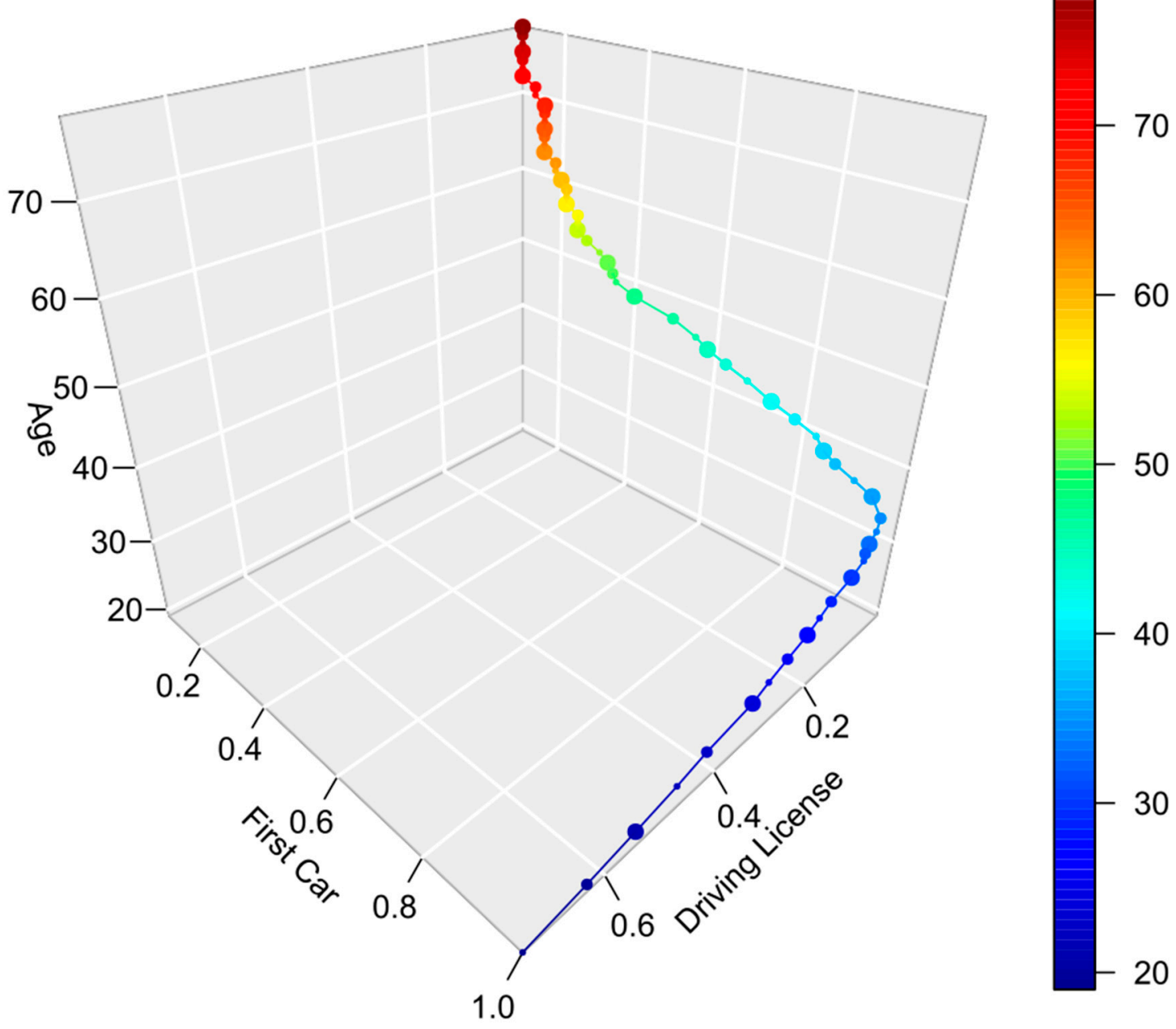

Figure 18. 3D Survival Curve showing the probability of getting a car driving license and getting a first car by age.

As can be observed by the pronounced curvature of the survival curve, during the first years of adulthood, only the chance of obtaining a car driving license is increased, while 
the chance of obtaining a first car remains very close to 0 , until the age of around 30 years old. Subsequently, the chance of obtaining a first car also starts to increase significantly. It appears younger ages often obtain a car driving license without obtaining a car.

Another noteworthy observation is the way different age groups and generations were found to differently affect the chance each mobility milestone had to happen through each respondent's lifetime. Different age groups were found to significantly affect how fast someone is likely to get their car driving license, their first vehicle as an adult (car or bicycle) and how likely they are to travel by airplane. Younger generations were more likely to get a car driving license and a car at a relatively older age, but more likely to get their first bike as adults or take their first airplane trip faster.

\section{Discussion and Conclusions}

As has been highlighted by the presented duration analysis, the various socio-economic characteristics and perceptions that have been examined, affect the Greek population's propensity to each mobility norm in different and often opposite ways. The results are summarized in Table 2. A more comprehensive summary of the results is provided in Appendix A.

Table 2. Summary of each characteristic's effect on each moblity milestone for characterstics affecting more than one mobility milestones.

\begin{tabular}{|c|c|c|c|c|c|}
\hline & $\begin{array}{c}\text { Getting a Car } \\
\text { Driving } \\
\text { License }\end{array}$ & $\begin{array}{l}\text { Getting Their } \\
\text { First Car }\end{array}$ & $\begin{array}{l}\text { Getting a } \\
\text { Motorbike } \\
\text { Driving } \\
\text { License }\end{array}$ & $\begin{array}{l}\text { Getting Their } \\
\text { First Bike as } \\
\text { Adults }\end{array}$ & $\begin{array}{c}\text { Taking Their First } \\
\text { Airplane Trip }\end{array}$ \\
\hline Gender & Higher for male & & Higher for male & & \\
\hline Age Group & $\begin{array}{l}\text { Higher for } \\
\text { Younger than } \\
45 \text { years }\end{array}$ & Higher for over 30 & & $\begin{array}{l}\text { Higher for } \\
\text { younger ages }\end{array}$ & $\begin{array}{l}\text { Higher for } \\
\text { younger ages }\end{array}$ \\
\hline $\begin{array}{l}\text { Parents' } \\
\text { Income }\end{array}$ & $\begin{array}{l}\text { Higher for higher } \\
\text { incomes }\end{array}$ & & $\begin{array}{l}\text { Higher for lower } \\
\text { incomes }\end{array}$ & & $\begin{array}{l}\text { Higher for higher } \\
\text { incomes }\end{array}$ \\
\hline $\begin{array}{c}\text { Use of a } \\
\text { private car by } \\
\text { family }\end{array}$ & $\begin{array}{l}\text { Higher if they used } \\
\text { one }\end{array}$ & & & & \\
\hline $\begin{array}{l}\text { Place they grew } \\
\text { up in }\end{array}$ & & $\begin{array}{l}\text { Higher for } \\
\text { villages }\end{array}$ & & $\begin{array}{l}\text { Higher for } \\
\text { cities }\end{array}$ & $\begin{array}{l}\text { Higher for } \\
\text { cities }\end{array}$ \\
\hline $\begin{array}{l}\text { Need of a } \\
\text { motorized } \\
\text { vehicle for } \\
\text { commuting }\end{array}$ & Higher with need & & Higher with need & & \\
\hline $\begin{array}{c}\text { Sustainable } \\
\text { Transport }\end{array}$ & & & $\begin{array}{l}\text { Higher for not } \\
\text { important }\end{array}$ & $\begin{array}{l}\text { Higher for } \\
\text { important }\end{array}$ & \\
\hline $\begin{array}{c}\text { Environmental } \\
\text { Awareness }\end{array}$ & & $\begin{array}{l}\text { Higher for not } \\
\text { important }\end{array}$ & & & \\
\hline
\end{tabular}

It is noteworthy that some of those characteristics have extended effects on a wide array of mobility norms, while others have not been found to be significant at all. Namely, their education and type of employment were not found to affect the temporal characteristics of mobility milestones to any significant degree. The current household income of the respondents was also not found to be significant, but the parent's household income during their first years of adulthood, affected how likely they were to get a car driving license or a motorbike driving license sooner and how young they first travelled by airplane for the first time. Interestingly, having parents with higher incomes that used private cars increased the chance of getting a car driving license sooner. On the contrary, having parents with lower incomes increased the chance of getting a motorbike driving license sooner. 
Additionally, growing up in villages has affected how likely it is to get private forms of transportation (both car or bicycle) sooner. The environment in which someone grew up appears to have a great effect on the choices they make later in life and how they fulfill their needs.

At the same time, part of current preferences, needs and predispositions also appear to change the mobility choices someone makes. Needing a motorized vehicle for commuting significantly increases both the chances of getting a car or motorbike license earlier on. Trips to work are a repeating ever-present need and they can significantly affect the mobilityoriented choices someone makes. Environmental awareness and the perceived importance of sustainable transport also translate into different choices, as environmentally aware Greeks are less likely to get a motorbike driving license or their first car sooner throughout their lifetimes. On the other hand, they are more likely to get their first bicycle earlier as adults. Environmental awareness has been found to be a deciding factor towards shifting away from cars [5] but also has been found not to be as important as other factors towards not getting a car driving license [6,7].

Gender was also found to affect the chance of getting either a car or motorbike driving license earlier, with men having greater chances of getting both sooner. This result makes sense, as traditionally men have been associated with higher levels of exposure to driving but at the same time they have been associated with higher chances of getting involved in accidents or incidents of reckless driving [79-81]. It appears that societal paradigms that narrate a higher male affinity to driving are still active in Greece and lead to men getting driving licenses sooner than average than compared to women.

Perhaps the most pronounced difference, documented through the analysis, was the effect the age group of the respondent had on the mobility choice made throughout each age group's lifetime. Distinct mobility profiles emerge that showcase the expected norms have drastically shifted in younger generations. Younger Greeks are much more likely to get a car driving license sooner but get their first car later compared to previous generations. At the same time, they have much greater chances of getting a bicycle as adults sooner. This could either be attributed to increased environmental awareness in younger ages, increased efforts on sustainable mobility campaigns, or to the economic crisis that rendered more expensive vehicle purchases prohibitive. But it is worth considering, that the propensity to get a first car sooner was not found to be affected by either the current income or their parents' income while growing up. This could suggest that the motivations behind this behavior were not monetary. Relevant research agrees with those results as it has shown a declining trend in car-based mobility in different countries for younger generations $[82,83]$ and that they are more likely to cycle [84-86]. Moreover, younger generations are more likely to travel by airplane for the first time in younger ages, something that is indicative of the airplane becoming a more approachable transport mode and of a continuously globalized lifestyle.

This paper explores lifetime mobility norms in Greece and identifies factors that most heavily affect them, with the use of duration analysis. However, the analysis is subject to limitations. First of all the observations that are made as a part of this study are geographically limited to Greece and as such, they are prone to local conditions, idiosyncrasies and predispositions, while the utilized sample is on the lower side for results to be derived for the whole Greek population. We consider as future step of our study the application of random sample generation techniques like that of Monte Carlo simulation for more robust outcomes [87]. Furthermore, a wider range of data, as well as the variation of some of those data with time (such as personal or family income, employment status and marital status) would offer more insight on their temporally varying effect on mobility preferences. As was mentioned in Section 2, the main drawback of using the Cox Proportional Hazards model is the proportional hazards assumption, that limits the analysis to only factors that have a set effect on the occurrence of the event over time. Moreover, while the examined factors that were included in the analysis are derived from the pertinent literature, there might be more that need to be considered, that could 
account for part of the unexplained variance or hide behind already examined factors. Yet beyond those limitations, it is worth considering that usually transport research is focused on determining the transport preferences certain groups of travelers seem to have in comparison to other groups of travelers with different characteristics. This often neglects the importance of the temporal and longitudinal dimensions of those events. Future research could focus on examining the evolution of mobility norms across more facets than those of private mobility, those of public transit and shared mobilities. Delving into how those norms evolve between different countries and cultures would also be of interest to explore differences and similarities. By expanding research efforts towards those areas, a deeper understanding of the mechanisms behind those choices can be achieved and because of that, more tailored methods for the prediction of the future transport landscape and demand and more thorough transport planning.

Author Contributions: Conceptualization, I.F. and I.P.; methodology, I.F. and I.P.; validation, I.F. and I.P.; investigation, I.F.; data curation, I.F.; writing—original draft preparation, I.F.; writing-review and editing, I.F. and I.P.; visualization, I.F.; supervision, I.P. All authors have read and agreed to the published version of the manuscript.

Funding: This research received no external funding.

Institutional Review Board Statement: Not applicable.

Informed Consent Statement: Informed consent was obtained from all subjects involved in the study.

Data Availability Statement: The data presented in this study are available on request from the corresponding author. The data are not publicly available due to terms and conditions that were accepted by the survey respondents.

Acknowledgments: The authors would like to thank the two anonymous reviewers that, through their comments, improved the article in its current version.

Conflicts of Interest: The authors declare no conflict of interest.

\section{Appendix A}

Table A1. Summary of the Hazard Ratios that were derived from the fitted Cox Proportional Hazards models

\begin{tabular}{|c|c|c|c|c|c|}
\hline & $\begin{array}{l}\text { Getting a Car } \\
\text { Driving } \\
\text { License }\end{array}$ & $\begin{array}{l}\text { Getting Their } \\
\text { First Car }\end{array}$ & $\begin{array}{l}\text { Getting a Motorbike } \\
\text { Driving } \\
\text { License }\end{array}$ & $\begin{array}{l}\text { Getting Their First } \\
\text { Bike as Adults }\end{array}$ & $\begin{array}{l}\text { Taking Their First } \\
\text { Airplane Trip }\end{array}$ \\
\hline \multicolumn{6}{|l|}{ Gender } \\
\hline Male & Reference & - & 4.56 & - & - \\
\hline Female & 0.46 & - & Reference & - & - \\
\hline \multicolumn{6}{|l|}{ Age Group } \\
\hline $18-30$ & & Reference & & Reference & Reference \\
\hline $31-45$ & & 1.89 & & 0.68 & 0.60 \\
\hline $46+$ & & 1.53 & & 0.16 & 0.37 \\
\hline \multicolumn{6}{|l|}{ Parents' Income } \\
\hline 0-1200 Euro & Reference & - & - & - & - \\
\hline 1201-2000+ Euro & $3.28 / 1.57^{1}$ & - & - & - & - \\
\hline \multicolumn{6}{|l|}{$\begin{array}{c}\text { Use of a } \\
\text { private car by family }\end{array}$} \\
\hline Yes & Reference & - & - & - & - \\
\hline No & 0.48 & - & - & - & - \\
\hline \multicolumn{6}{|l|}{ Place they grew up in } \\
\hline Village & - & Reference & - & Reference & $0.68^{2}$ \\
\hline Town & - & 0.40 & - & 0.34 & \\
\hline City & - & 0.66 & - & 0.74 & Reference \\
\hline \multicolumn{6}{|l|}{$\begin{array}{l}\text { Need of a motorized } \\
\text { vehicle for commuting }\end{array}$} \\
\hline $\begin{array}{l}\text { Yes, with a } \\
\text { motorized vehicle }\end{array}$ & Reference & & 2.67 & - & \\
\hline No/Yes, walking or cycling & 0.53 & & Reference & - & \\
\hline
\end{tabular}


Table A1. Cont.

\begin{tabular}{|c|c|c|c|c|c|}
\hline & $\begin{array}{c}\text { Getting a Car } \\
\text { Driving } \\
\text { License }\end{array}$ & $\begin{array}{c}\text { Getting Their } \\
\text { First Car }\end{array}$ & $\begin{array}{c}\text { Getting a Motorbike } \\
\text { Driving } \\
\text { License }\end{array}$ & $\begin{array}{l}\text { Getting Their First } \\
\text { Bike as Adults }\end{array}$ & $\begin{array}{c}\text { Taking Their First } \\
\text { Airplane Trip }\end{array}$ \\
\hline \multicolumn{6}{|l|}{ Sustainable Transport } \\
\hline Neutral & - & 1 & Reference & Reference & \\
\hline \multicolumn{6}{|l|}{ Unimportant } \\
\hline \multicolumn{6}{|l|}{ Very Unimportant } \\
\hline \multicolumn{6}{|l|}{ Very Important } \\
\hline Important & - & 1 & 0.47 & 1.79 & \\
\hline \multicolumn{6}{|l|}{ Environmental Awareness } \\
\hline Very Important & - & Reference & - & - & \\
\hline Important & - & 1.28 & - & - & \\
\hline Neutral & - & 0.76 & - & - & \\
\hline Unimportant & - & 1.99 & - & - & \\
\hline Very Unimportant & - & 13.61 & - & - & \\
\hline \multicolumn{6}{|l|}{ License Necessity } \\
\hline Somewhat Necessary & Reference & - & - & - & \\
\hline \multicolumn{6}{|l|}{ A Little Necessary } \\
\hline \multicolumn{6}{|l|}{ Not Necessary } \\
\hline \multicolumn{6}{|l|}{ Very Necessary } \\
\hline Necessary & 2.54 & - & - & - & \\
\hline
\end{tabular}

${ }^{1}$ First value refers to the effect for ages 18-20, while the second for ages $20+.{ }^{2}$ For this mobility milestone the hazard ratio referes to both

"Village" and "Town" with "City" being the reference level.

\section{References}

1. Kuhnimhof, T.; Buehler, R.; Dargay, J. A New Generation: Travel Trends among young Germans and Britons. In Proceedings of the 90th Annual Meeting of the Transportation Research Board, Washington, DC, USA, 23-27 January 2011.

2. Kuhnimhof, T.; Armoogum, J.; Buehler, R.; Dargay, J.; Denstadli, J.M.; Yamamoto, T. Men Shape a Downward Trend in Car Use among Young Adults-Evidence from Six Industrialized Countries. Transp. Rev. 2012, 32, 761-779. [CrossRef]

3. Keyes, A.K.M.; Crawford-Brown, D. The changing influences on commuting mode choice in urban England under Peak Car: A discrete choice modelling approach. Transp. Res. Part F Traffic Psychol. Behav. 2018, 58, 167-176. [CrossRef]

4. Clark, B.; Chatterjee, K.; Melia, S. Changes in level of household car ownership: The role of life events and spatial context. Transportation 2016, 43, 565-599. [CrossRef]

5. Clark, B.; Chatterjee, K.; Melia, S. Changes to commute mode: The role of life events, spatial context and environmental attitude. Transp. Res. Part A Policy Pract. 2016, 89, 89-105. [CrossRef]

6. Le Vine, S.; Jones, P.; Lee-Gosselin, M.; Polak, J. Is heightened environmental sensitivity responsible for drop in young adults' rates of driver's license acquisition? Transp. Res. Rec. 2014, 2465, 73-78. [CrossRef]

7. Hopkins, D. Can environmental awareness explain declining preference for car-based mobility amongst generation Y? A qualitative examination of learn to drive behaviours. Transp. Res. Part A Policy Pract. 2016, 94, 149-163. [CrossRef]

8. Pojani, E.; Van Acker, V.; Pojani, D. Cars as a status symbol: Youth attitudes toward sustainable transport in a post-socialist city. Transp. Res. Part F Traffic Psychol. Behav. 2018, 58, 210-227. [CrossRef]

9. Belgiawan, P.F.; Schmöcker, J.D.; Abou-Zeid, M.; Walker, J.; Fujii, S. Modelling social norms: Case study of students' car purchase intentions. Travel Behav. Soc. 2017, 7, 12-25. [CrossRef]

10. Delbosc, A.; Currie, G. Causes of Youth Licensing Decline: A Synthesis of Evidence. Transp. Rev. 2013, 33, 271-290. [CrossRef]

11. Newbold, K.B.; Scott, D.M. Driving over the life course: The automobility of Canada's Millennial, Generation X, Baby Boomer and Greatest Generations. Travel Behav. Soc. 2017, 6, 57-63. [CrossRef]

12. Oakil, A.T.M. Securing or sacrificing access to a car: Gender difference in the effects of life events. Travel Behav. Soc. 2016, 3, 1-7. [CrossRef]

13. Mayne, K.; Baltatzi, E. European Bicycle Market Analysis 2015; European Cyclists' Federation: Brussels, Belgium, 2015.

14. Sigurdardottir, S.B.; Kaplan, S.; Møller, M.; Teasdale, T.W. Understanding adolescents' intentions to commute by car or bicycle as adults. Transp. Res. Part D Transp. Environ. 2013, 24, 1-9. [CrossRef]

15. Nikitas, A. Understanding bike-sharing acceptability and expected usage patterns in the context of a small city novel to the concept: A story of 'Greek Drama'. Transp. Res. Part F Traffic Psychol. Behav. 2018, 56, 306-321. [CrossRef]

16. De Neufville, R.; Odoni, A. Airport Systems, Planning Design and Management; McGraw-Hill Education: New York, NY, USA, 2013.

17. Tao, S.; He, S.Y.; Thøgersen, J. The role of car ownership in attitudes towards public transport: A comparative study of Guangzhou and Brisbane. Transp. Res. Part F Traffic Psychol. Behav. 2019, 60, 685-699. [CrossRef]

18. Brittanica Encyclopedia Brittanica Encyclopedia-Greece. Available online: https://www.britannica.com/place/Greece/Religion (accessed on 16 November 2020).

19. The Economist Acropolis Now. Available online: https://www.economist.com/leaders/2010/04/29/acropolis-now (accessed on 16 November 2020). 
20. Tue New York Times The Euro Is a Straitjacket for Greece. Available online: https://www.nytimes.com/roomfordebate/2015/0 6/30/should-greece-abandon-the-euro/the-euro-is-a-straitjacket-for-greece (accessed on 16 November 2020).

21. Kyriakidis, A. The Greek Crisis 2009-2015: A Comprehensive Analysis of the EU-IMF Financial Assistance Programs. Int. J. Employ. Stud. 2016, 24, 7.

22. Statista Research Department Number of Passenger Cars per 1000 Inhabitants in Greece from 1990 to 2017. Available online: https: / / www.statista.com/statistics/452020/greece-number-of-cars-per-1000-inhabitants/ (accessed on 16 November 2020).

23. Lalioti, K.M. Carsharing: The Study of an Innovative and Ecological Way of Transport. Master's Thesis, University of Piraeus, Pireas, Greece, 2012.

24. City of Thessaloniki, Metropolitan Development Agency of Thessaloniki. Resilient Thessaloniki: A Strategy for 2030. THEPTA Report (In Greek); Thessaloniki Public Transport Authority (THEPTA): Thessaloniki, Greece, 2020.

25. Bakogiannis, E.; Siti, M.; Tsigdinos, S.; Vassi, A.; Niksitas, A. Monitoring the first dockless bike sharing system in Greece: Understanding user perceptions, usage patterns and adoption barriers. Res. Transp. Bus. Manag. 2019, 33, 100432. [CrossRef]

26. Politis, I.; Papadopoulos, E.; Fyrogenis, I.; Nikolaidou, A.; Delivopoulos, G.; Tsampouris, I. WP 2.1 Building 4-Stage Travel Demand Model; CHANGE Project: Thessaloniki, Greece, 2019.

27. Rodriguez, G. Lecture Notes on Generilized Linear Models. Available online: http://data.princeton.edu/wws509/notes/ (accessed on 16 November 2020).

28. Klein, J.P.; Moeschberger, M.L. SURVIVAL ANALYSIS Techniques for Censored and Truncated Data, 2nd ed.; Springer: New York, NY, USA, 2003.

29. Jovanis, P.; Chang, H.L. Disaggregate model of highway accident occurrence using survival theory. Accid. Anal. Prev. 1989, 21, 445-458. [CrossRef]

30. Hansher, D.A.; Mannering, F.L. Hazard-based duration models and their application to transport analysis. Transp. Rev. 1994, 14, 63-82. [CrossRef]

31. Sexton, B.; Grayson, G. Further Analyses of Accident Data from the Cohort II Study: When Do Drivers Have Their First Accident and Does It Have an Impact on Their Subsequent Driving? Transport Research Laboratory: Crowthorne, UK, 2009.

32. Shin, H.C.; Madanat, S. Development of a stochastic model of pavement distress initiation. J. Infrastruct. Plan. Man. 2003, 4, 61-67. [CrossRef]

33. Loizos, A.; Karlaftis, M.G. Prediction of Pavement Crack Initiation from In-Service Pavements A Duration Model Approach. Transp. Res. Rec. J. Transp. Res. Board. 2005, 1940, 38-42. [CrossRef]

34. Vlahogianni, E.I. Modeling duration of overtaking in two lane highways. Transp. Res. Part F Traffic Psychol. Behav. 2013, 20, 135-146. [CrossRef]

35. Dorantes Argandar, G.; Tortosa Gil, F.; Ferrero Berlanga, J. Measuring situations that stress Mexicans while driving. Transp. Res. Part F Traffic Psychol. Behav. 2016, 37, 154-161. [CrossRef]

36. Choudhary, P.; Velaga, N.R. Modelling driver distraction effects due to mobile phone use on reaction time. Transp. Res. Part C 2017, 77, 351-365. [CrossRef]

37. Yadav, A.K.; Velaga, N.R. Modelling the relationship between different Blood Alcohol Concentrations and reaction time of young and mature drivers. Transp. Res. Part F Traffic Psychol. Behav. 2019, 64, 227-245. [CrossRef]

38. Tiwari, G.; Bangdiwala, S.; Saraswat, A.; Gaurav, S. Survival analysis: Pedestrian risk exposure at signalized intersections. Transp. Res. Part F 2007, 10, 77-89. [CrossRef]

39. Yang, X.; Huan, M.; Si, B.; Gao, L.; Guo, H. Crossing at a Red Light: Behavior of Cyclists at Urban Intersections. Res. Artic. 2012. [CrossRef]

40. Mannering, F.L.; Hamed, M.M. Occurence, frequency, and duration of commuters' work-to-home departure delay. Transp. Res. Part B 1990, 24, 99-109. [CrossRef]

41. Mannering, F.; Murakami, E.; Kim, S.-G. Temporal stability of travelers' activity choice and home-stay duration: Some empirical evidence. Transportation 1994, 21, 371-392. [CrossRef]

42. Lee, E.T.; Wang, J.W. Statistical Methods for Survival Data Analysis, 3rd ed.; John Wiley \& Sons, Inc.: Hoboken, NJ, USA, 2003.

43. Kleinbaum, D.G.; Klein, M. Survival Analysis A Self-Learning Text, 3rd ed.; Springer: New York, NY, USA, 2012.

44. Cox, D.R. Regression Models and Life-Tables. J. R. Stat. Soc. Ser. B 1973, 34, 187-220.

45. Donev, V.; Hoffmann, M. Condition prediction and estimation of service life in the presence of data censoring and dependent competing risks. Int. J. Pavement Eng. 2017, 20, 313-331. [CrossRef]

46. Clark, T.G.; Bradburn, M.J.; Love, S.B.; Altman, D.G. Surival Analysis Part I: Basic concepts and first analyses. Br. J. Cancer 2003, 89, 232-238. [CrossRef]

47. Onwezen, M.C.; Bartels, J. Which perceived characteristics make product innovations appealing to the consumer? A study on the acceptance of fruit innovations using cross-cultural consumer segmentation. Appetite 2011, 57, 50-58. [CrossRef] [PubMed]

48. Abeliotis, K.; Koniari, C.; Sardianou, E. The profile of the green consumer in Greece. Int. J. Consum. Stud. 2010, 34, 153-160. [CrossRef]

49. R Core Team. R: A Language and Environment for Statistical Computing; R Foundation for Statistical Computing: Vienna, Austria, 2020.

50. Wickham, H.; Roamain, F.; Lionel, H.; Kirill, M. Dplyr: A Grammar of Data Manipulation; R Package Version 0.7.6; 2018. Available online: https:/ / cran.r-project.org/web/packages/dplyr/index.html (accessed on 16 November 2020). 
51. Therneau, T.; Grambsch, P.; Fleming, T. A Package for Survival Analysis in S; Springer: New York, NY, USA, 2015.

52. Kassambara, A.; Kosinski, M. Survminer: Drawing Survival Curves Using "ggplot2"; R Package Version 0.4.2; 2018. Available online: https: / / cran.r-project.org/web / packages/survminer/index.html (accessed on 16 November 2020).

53. Jackson, C. \{flexsurv\}: A Platform for Parametric Survival Modeling in \{R\}. J. Stat. Softw. 2016, 70, 8. [CrossRef] [PubMed]

54. Wickham, H. ggplot2: Elegant Graphics for Data Analaysis; Springer: New York, NY, USA, 2016.

55. Arnold, J.B. ggthemes: Extra Themes, Scale and Geoms for "ggplot2"; R Package Version 4.0.1. 2018. Available online: https: / /rdrr.io/cran/ggthemes/ (accessed on 28 April 2021).

56. Venables, W.N.; Ripley, B.D. Modern Applied Statistics with S, 4th ed.; Springer: New York, NY, USA, 2002; ISBN 0-387-95457-0.

57. Fox, J.; Weisberg, S. An $\{R\}$ Companion to Applied Regression, 3rd ed.; Sage: Thousand Oaks, CA, USA, 2019.

58. Soetaert, K. plot3D: Plotting Multi-Dimensional Data; 2019. Available online: https://cran.r-project.org/web/packages/plot3D/ index.html (accessed on 16 November 2020).

59. Soetaert, K. plot3Drgl: Plotting Multi-Dimensional Data-Using "rgl"; R Package Version 1.0.1; 2016. Available online: https: / / cran.r-project.org/web/packages/plot3Drgl/index.html (accessed on 16 November 2020).

60. Kennedy, N. forestmodel: Forest Plots from Regression Models; 2020. Available online: https://cran.r-project.org/web/packages/ forestmodel/index.html (accessed on 16 November 2020).

61. Collet, D. Modelling Survival Data in Medical Research, 3rd ed.; Chapman \& Hall/CRC: Boca Raton, FL, USA, 2014.

62. Vittinghoff, E.; McCulloch, C.E. Relaxing the Rule of Ten Events per Variable in Logistic and Cox Regression. Am. J. Epidemiol. 2007, 165, 710-718. [CrossRef] [PubMed]

63. Republic of Greece Government Gazette. Presidential Decree \# 51; Republic of Greece: Athens, Greece, 2012.

64. Prieto, M.; Caemmerer, B. An exploration of factors influencing car purchasing decisions. Int. J. Retail Distrib. Manag. 2013, 41, 738-764. [CrossRef]

65. Klein, N.J.; Smart, M.J. Millennials and car ownership: Less money, fewer cars. Transp. Policy 2017, 53, 20-29. [CrossRef]

66. Pyddoke, R.; Creutzer, C. Household Car Ownership in Urban and Rural Areas in Sweden 1999-2008; Working papers in transport economics; CTS—Centre for Transport Studies Stockholm: Stockholm, Sweden, 2014.

67. Carroll, P.; Benevenuto, R.; Caulfield, B. Identifying Hotspots of Transport Disadvantage and Car Dependency in Rural Ireland. Transp. Policy 2020, 101, 46-56. [CrossRef]

68. Kopp, P. The unpredicted rise of motorcycles: A cost benefit analysis. Transp. Policy 2011, 18, 613-622. [CrossRef]

69. Heinen, E.; van Wee, B.; Maat, K. Commuting by Bicycle: An Overview of the Literature. Transp. Rev. A Transnatl. Transdiscipl. J. 2010, 30, 59-96. [CrossRef]

70. Handy, S.L.; Xing, Y.; Buehler, T.J. Factors associated with bicycle ownership and use: A study of six small U.S. cities. Transportation 2010, 37, 967-985. [CrossRef]

71. Akar, G.; Clifton, K.J. Influence of individual perceptions and bicycle infrastructure on decision to bike. Transp. Res. Rec. 2009, 2140, 165-172. [CrossRef]

72. Rietveld, P.; Daniel, V. Determinants of bicycle use: Do municipal policies matter? Transp. Res. Part A Policy Pract. 2004, 38, 531-550. [CrossRef]

73. European Cyclists' Federation ECF Cycling Barometer. Available online: https:/ / ecf.com/resources/cycling-facts-and-figures / ecf-cycling-barometer (accessed on 16 November 2020).

74. Aggelidou, T.V. Municipality of Thessaloniki: Bicycle Master Plan. Master's Thesis, Aristotle University of Thessaloniki, Thessaloniki, Greece, 2016.

75. Confederation of the European Bicycle Industry. European Bicycle Market; Springer: Brussels, Belgium, 2016.

76. European Parliament. The promotion of cycling. Policy Dep. B Struct. Cohes. Policies Transp. Tour. 2010, 1-74. Available online: https:/ / www.ecf.com/sites/ecf.com/files/European-Parliament-2010_Promotion-of-Cycling.pdf (accessed on 16 November 2020).

77. Heinen, E.; Maat, K.; Van Wee, B. The role of attitudes toward characteristics of bicycle commuting on the choice to cycle to work over various distances. Transp. Res. Part D Transp. Environ. 2011, 16, 102-109. [CrossRef]

78. Halldórsdóttir, K.; Christensen, L.; Jensen, T.C.; Prato, C.G.; Giacomo, C.; Linda Christensen, B.; Thomas Christian Jensen, B.; Carlo Giacomo Prato, B. Modelling Mode Choice in Short Trips-Shifting from Car to Bicycle. In Proceedings of the European Transport Conference, Glasgow, UK, 10-12 October 2011.

79. González-Iglesias, B.; Gómez-Fraguela, J.A.; Luengo-Martín, M.Á. Driving anger and traffic violations: Gender differences. Transp. Res. Part F Traffic Psychol. Behav. 2012, 15, 404-412. [CrossRef]

80. Bergdahl, J. Sex differences in attitudes toward driving: A survey. Soc. Sci. J. 2005, 42, 595-601. [CrossRef]

81. Özkan, T.; Lajunen, T. What causes the differences in driving between young men and women? The effects of gender roles and sex on young drivers' driving behaviour and self-assessment of skills. Transp. Res. Part F Traffic Psychol. Behav. 2006, 9, 269-277. [CrossRef]

82. Hjorthol, R. Decreasing popularity of the car? Changes in driving licence and access to a car among young adults over a 25-year period in Norway. J. Transp. Geogr. 2016, 51, 140-146. [CrossRef]

83. Sivak, M.; Schoettle, B. Recent changes in the age composition of drivers in 15 countries. Traffic Inj. Prev. 2012, 13, 126-132. [CrossRef] 
84. Haustein, S.; Møller, M. Age and attitude: Changes in cycling patterns of different e-bike user segments. Int. J. Sustain. Transp. 2016, 10, 836-846. [CrossRef]

85. Dill, J. Are Millennials Really the Generation That Bikes? Available online: https://trec.pdx.edu/blog/are-millennials-reallygeneration-bikes (accessed on 31 March 2021).

86. Burrows, M. Younger Workers in Cities More Likely to Bike to Work. Available online: https://www.census.gov/library/stories/ 2019/05/younger-workers-in-cities-more-likely-to-bike-to-work.html (accessed on 31 March 2021).

87. Barabino, B.; Cabras, N.A.; Conversano, C.; Olivo, A. An Integrated Approach to Select Key Quality Indicators in Transit Services. Soc. Indic. Res. 2020, 149, 1045-1080. [CrossRef] 